\title{
Cooperation between both Wnt/ $\beta$-catenin and PTEN/PI3K/Akt signaling promotes primitive hematopoietic stem cell self-renewal and expansion
}

\author{
John M. Perry, ${ }^{1}$ Xi C. He, ${ }^{1}$ Ryohichi Sugimura, ${ }^{1}$ Justin C. Grindley, ${ }^{1,4}{ }^{\text {Jeffrey S. Haug, }}{ }^{1}$ \\ Sheng Ding, ${ }^{2}$ and Linheng $\mathrm{Li}^{1,3,5}$ \\ ${ }^{1}$ Stowers Institute for Medical Research, Kansas City, Missouri 64110, USA; ${ }^{2}$ Department of Chemistry, Scripps Research \\ Institute, La Jolla, California 92037, USA; ${ }^{3}$ Department of Pathology and Laboratory Medicine, Kansas University Medical \\ Center, Kansas City, Kansas 66160, USA
}

\begin{abstract}
Although self-renewal is the central property of stem cells, the underlying mechanism remains inadequately defined. Using a hematopoietic stem and progenitor cell (HSPC)-specific conditional induction line, we generated a compound genetic model bearing both Pten deletion and $\beta$-catenin activation. These double mutant mice exhibit a novel phenotype, including expansion of phenotypic long-term hematopoietic stem cells (LT-HSCs) without extensive differentiation. Unexpectedly, constitutive activation of $\beta$-catenin alone results in apoptosis of HSCs. However, together, the Wnt/ß-catenin and PTEN/PI3k/Akt pathways interact to drive phenotypic LT-HSC expansion by inducing proliferation while simultaneously inhibiting apoptosis and blocking differentiation, demonstrating the necessity of complementary cooperation between the two pathways in promoting self-renewal. Mechanistically, $\beta$-catenin activation reduces multiple differentiation-inducing transcription factors, blocking differentiation partially through up-regulation of Inhibitor of differentiation 2 (Id2). In double mutants, loss of Pten enhances the HSC anti-apoptotic factor Mcl-1. All of these contribute in a complementary way to HSC selfrenewal and expansion. While permanent, genetic alteration of both pathways in double mutant mice leads to expansion of phenotypic HSCs, these HSCs cannot function due to blocked differentiation. We developed a pharmacological approach to expand normal, functional HSCs in culture using factors that reversibly activate both Wnt/B-catenin and PI3K/Akt signaling simultaneously. We show for the first time that activation of either single pathway is insufficient to expand primitive HSCs, but in combination, both pathways drive self-renewal and expansion of HSCs with long-term functional capacity.
\end{abstract}

[Keywords: $\beta$-catenin; PTEN; hematopoietic stem cells; self-renewal; ex vivo expansion]

Supplemental material is available for this article.

Received January 5, 2011; revised version accepted August 11, 2011.

Self-renewal allows stem cells to replicate throughout an organism's life span without losing developmental potential (Orkin 2000). Preventing differentiation is required for self-renewal (Ying et al. 2008). Conversely, imposing differentiation on proliferating stem cells-or apoptosis for stem cells that fail to properly differentiate-is critical to hematopoietic stem cell (HSC) homeostasis and cancer prevention (Reya et al. 2001). The stem cell pool is not static, however. During development or in response to acute stress, stem cells may transiently expand by symmetric division, where both daughter cells remain undifferenti-

\footnotetext{
${ }^{4}$ Present address: Pfizer, 235 East 42nd St., New York, NY 10017, USA. ${ }^{5}$ Corresponding author.

E-mail lil@stowers.org.

Article published online ahead of print. Article and publication date are online at http://www.genesdev.org/cgi/doi/10.1101/gad.17421911.
}

ated stem cells (Morrison and Kimble 2006; Orkin and Zon 2008).

Wnt signaling is important for self-renewal of stem cells from multiple tissues (van de Wetering et al. 2002; Reya et al. 2003; Ying et al. 2008; Blanpain and Fuchs 2009). However, the role of Wnt $/ \beta$-catenin signaling in HSCs is particularly complex and cannot be generalized, leading to controversy in the field (Malhotra and Kincade 2009). $\beta$-catenin has been reported to be dispensable for HSC function, with loss of $\beta$-catenin and even simultaneous loss of both $\beta$-catenin and its closely related paralog, $\gamma$-catenin, failing to affect homeostatic hematopoiesis and repopulation capacity of HSCs from adult mice (Cobas et al. 2004; Jeannet et al. 2008; Koch et al. 2008). Others have reported that loss of $\beta$-catenin at the embryonic stage-during which the HSC pool undergoes substantial expansion-impairs 
the long-term growth and maintenance of adult HSCs following transplantation (Zhao et al. 2007). Addition of Wnt proteins or retroviral expression of constitutively active $\beta$-catenin has been reported to expand HSCs with at least short-term functional activity in culture (Murdoch et al. 2003; Reya et al. 2003; Willert et al. 2003; Baba et al. 2005; Nemeth et al. 2007); however, despite being first reported more than a decade ago, these methods have not been translated to the clinic. Similarly, in vivo administration of a chemical inhibitor of GSK3 $\beta$, a factor involved in degradation of $\beta$-catenin, improves hematopoietic repopulation and survival of HSC transplant recipients (Trowbridge et al. 2006). However, genetic disruption of Gsk3 leads to progressive depletion of HSCs (Huang et al. 2009). In vivo studies of mice expressing a stabilized, active allele of $\beta$-catenin also resulted in hematopoietic failure and loss of HSC repopulating activity (Kirstetter et al. 2006; Scheller et al. 2006). This was proposed to be due to blocked differentiation and enforced cell cycle entry, leading to HSC exhaustion. More recently, the role of Wnt signaling from the HSC osteoblast niche was examined. Osteoblast-specific expression of the pan-canonical Wnt signaling inhibitor Dickkopf1 (Dkk1) inhibited Wnt signaling in HSCs in vivo and surprisingly resulted in increased cell cycling and progressive loss of repopulation capacity. This indicated that Wnt signaling from the niche serves to enforce HSC quiescence and thereby preserve long-term functional potential (Fleming et al. 2008). It is notable, however, that Dkk1 transgenic mice exhibited significantly reduced trabecular bone volume-an area enriched in the HSC niche-which raises the possibility of additional effects beyond Wnt signaling (Li et al. 2006; Fleming et al. 2008). It seems that Wnt signaling yields complex, dose-dependent effects that are highly influenced by physiological context (Fleming et al. 2008; Malhotra and Kincade 2009). Overall, the role of Wnt/ $\beta$-catenin signaling in HSC self-renewal continues to be unclear, and much remains to be learned from this critical signaling pathway regarding self-renewal.

The importance of maintaining rare, relatively quiescent HSCs has been illustrated in mice with conditional deletion of the tumor suppressor PTEN (Rossi and Weissman 2006; Yilmaz et al. 2006; J Zhang et al. 2006). PTEN's main function is to negatively regulate the PI3K-Akt pathway. Loss of PTEN results in overactive Akt, which induces proliferation and promotes survival by inhibiting apoptosis (Datta et al. 1997; Salmena et al. 2008). Mx1-Cre-mediated conditional loss of Pten results in proliferation and mobilization of HSCs from bone marrow (BM), followed by transient expansion in the spleen, but ultimately leads to HSC depletion. PTEN-deficient mice die of myeloproliferative disorder (MPD) or its progression to leukemia (Yilmaz et al. 2006; J Zhang et al. 2006; Guo et al. 2008).

Using an animal model that allows hematopoietic stem and progenitor cell (HSPC)-specific conditional deletion and also avoids the HSC-stimulating effects of interferon (INF) induction (Gothert et al. 2005), we studied the effects of Pten deletion combined with activation of $\beta$-catenin. Although self-renewal is frequently discussed as if it were a discrete phenomenon, it can be broken down into a combination of three phenomena: (1) proliferation, (2) inhibition of apoptosis, and (3) inhibition of differentiation (Zhang and Li 2005). However, for normal, long-term homeostasis, these phenomena involve compromises that must be balanced (Scadden 2006).

Phenotypic HSCs from double mutant mice combining loss of PTEN with activated $\beta$-catenin exhibit permanent impairment of differentiation that prevents their ability to function. However, informed by our genetic model, we used a pharmacological approach to activate both the PI3K/ Akt and Wnt/ $\beta$-catenin signaling pathways to expand normal, functional long-term HSCs (LT-HSCs) in culture. This culture method is dependent on stimulation of the PI3K/ Akt pathway and additional activation of $\mathrm{Wnt} / \beta$-catenin signaling via small molecule inhibition of GSK $3 \beta$, which results in ex vivo expansion of functional LT-HSCs in particular-an effect apparent only after serial, long-term transplantation. We show that activation of either single pathway is not sufficient for LT-HSC self-renewal; rather, both pathways contribute cooperative effects to self-renewal, revealing a new mechanism for driving HSC expansion. Our ex vivo HSC expansion protocol achieves long-term engraftment equivalent to a 100-fold greater dosage of uncultured HSCs, even in three-generation, serial transplant recipients. Using serum-free medium with low doses of cytokines but without using feeder cell layers or permanent genetic manipulation, our protocol is ideal for potential translation into the clinic.

\section{Results}

In vivo expansion of phenotypic HSCs in double mutants

We generated a mouse model combining conditional Pten deletion (Lesche et al. 2002) with conditional constitutive activation of $\beta$-catenin $\left(\beta\right.$-cat $\left.{ }^{A c t}\right)\left(C t n n b 1^{\text {tm } 1 M m t}\right)$ (Harada et al. 1999). In the tissue-nonspecific induction system (Mx1-Cre), double mutants exhibited severe defects in multiple tissues that made it impossible to complete long-term studies specifically in the hematopoietic system (data not shown). Consequently, we used tamoxifen-inducible HSC$S C L-C r e-E R^{T}$ (hereafter referred to as Scl-Cre), which allowed us to study effects initiated primarily from HSPCs (Gothert et al. 2005). We observed only modest changes in the hematopoietic system of single and double mutants relative to control at $10 \mathrm{~d}$ post-induction (dpi) as well as 4 wk post-induction (wpi) (data not shown). However, at 6 wpi, double mutants exhibited a novel phenotype. HSCs in mice are highly enriched in LSK cells (lineage-negative, Sca- $1^{+}, \mathrm{Kit}^{+}$, with long-term repopulating HSCs specified in the $\mathrm{CD}^{-} 4^{-} \mathrm{Flk2} 2^{-}$fraction of LSK cells (Osawa et al. 1996; Christensen and Weissman 2001; Purton and Scadden 2007). The frequency of LSK cells significantly increased in both BM and especially the spleen. However, the frequency of more mature progenitor cells (lineagenegative, Sca- ${ }^{-}, \mathrm{Kit}^{+}$cells) decreased in both $\mathrm{BM}$ and the spleen in double mutants, indicating a failure of myeloid differentiation (Fig. 1A,B). Interestingly, within the LSK population, double mutants exhibited a higher frequency of both Flk2 ${ }^{-}$and $\mathrm{CD} 34^{-}$cells than did 

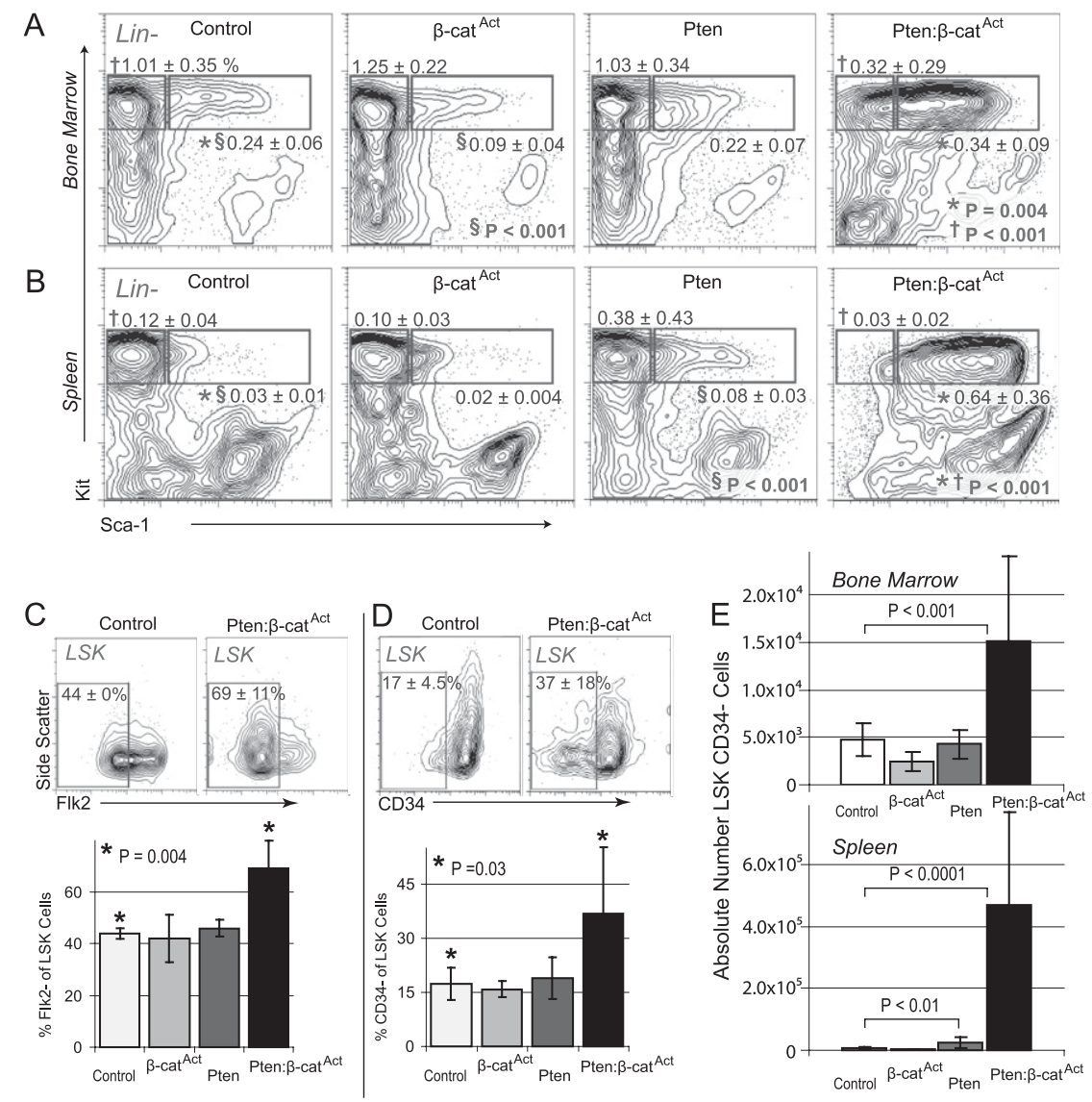

Figure 1. In vivo expansion of double mutant phenotypic HSCs. $(A, B)$ FACS (fluorescence activated cell sorting) diagrams (pregated for lineage-negative [ $\left.\mathrm{Lin}^{-}\right]$cells) of LSK cells (right blue box) and myeloid progenitors (left blue box) in control, single mutant, and double mutant BM and spleen as indicated at 6 wpi. Mean frequencies are based on total cell number $\pm \mathrm{SD}$. $(C, D)$ Frequency of Flk2 $2^{-}$and CD $34^{-}$cells within the LSK population in control, single mutants, and double mutants at 6 wpi. $(E)$ Absolute number of LSK CD34- cells in control, single mutant, and double mutant $\mathrm{BM}$ (tibia + femur) and spleen at 6 wpi. control or either single mutant (Fig. 1C,D). In addition to frequency, the absolute number of LSK CD34- cells was also significantly increased in both BM and the spleen of double mutants compared with both control and single mutants (Fig. 1E). Despite the substantial increase in phenotypic HSCs, further characterization of early myeloid progenitors showed that both the frequency and absolute number of common myeloid progenitors (CMPs), megakaryocyte-erythroid progenitors (MEPs), and granulocyte-monocyte progenitors (GMPs) were significantly reduced in double mutants; however, the frequency and absolute number of common lymphoid progenitors (CLPs) was neither increased nor deceased (Fig. 2A,B; Kondo et al. 1997; Akashi et al. 2000). These data demonstrate that phenotypic HSCs are substantially expanded in double mutants compared with control and single mutants. Furthermore, this expansion is coupled with reduced differentiation of CMPs, MEPs, and GMPs but without significant corresponding increases in early lymphoid differentiation.

By 6 wpi, approximately one-half of double mutants began to develop leukemia with substantial blast cell (CD45 $5^{\text {High }}$ ) populations (Borowitz et al. 1993). By 10-11 wpi, all double mutants had severe T-cell acute lymphocytic leukemia (T-ALL) and required euthanasia (data not shown). These leukemic mice were excluded from the analyses presented in Figures 1 and 2.
Transplanted double mutant LSK Flk2- cells are maintained as phenotypic HSCs in vivo

We bred control, single mutants, and double mutants with the $Z / E G$ reporter line in order to trace cells that had undergone Cre-mediated excision of their floxed alleles (Novak et al. 2000). This reporter system activates expression of enhanced green fluorescent protein (EGFP) upon Cre-mediated excision. One-thousand sorted LSK Flk2 ${ }^{-}$cells from control, single mutant, and double mutant $Z / E G$ mice $\left(\mathrm{CD} 45.2^{+}\right)$were transplanted along with $2 \times 10^{5}$ competitor $\left(\mathrm{CD} 45.1^{+}\right) \mathrm{BM}$ cells into lethally irradiated CD45.1 $1^{+}$ recipients. Due to the declining health of mice transplanted with double mutant LSK Flk2 ${ }^{-}$cells, we sacrificed recipients at 9 wpi (Fig. 3A). Given the impaired myeloid differentiation and accumulation of phenotypic HSCs in double mutants, we tested whether mutant LSK Flk2 ${ }^{-}$cells were maintained in recipient mice. We gated LSK Flk2 ${ }^{-}$cells in each recipient group and observed GFP expression in this subpopulation. Mice transplanted with wild-type Scl-Cre ${ }^{+}$Z/EG donor LSK Flk2- cells maintained $43 \% \pm$ $5.4 \% \mathrm{EGFP}^{+}$LSK Flk2 ${ }^{-}$cells. However, Pten-Z/EG transplant recipients maintained only a minor portion of LSK Flk2 ${ }^{-}$cells that were $\mathrm{EGFP}^{+}(8.6 \% \pm 2.1 \%)$, demonstrating that some Pten mutant LSK Flk2 ${ }^{-}$cells remained even after 9-10 wpi. Considering the high frequencies of total donor-derived cells in Pten transplant recipients 
A
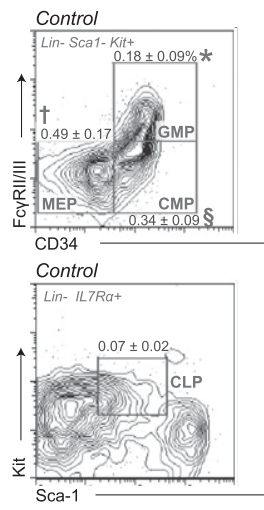

Pten: $\beta$-cat ${ }^{A c t}$

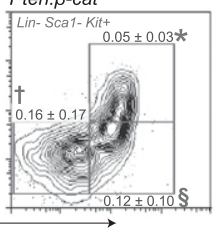

Pten: $\beta$-cat ${ }^{\text {Act }}$

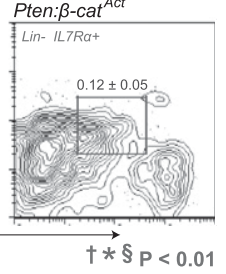

B

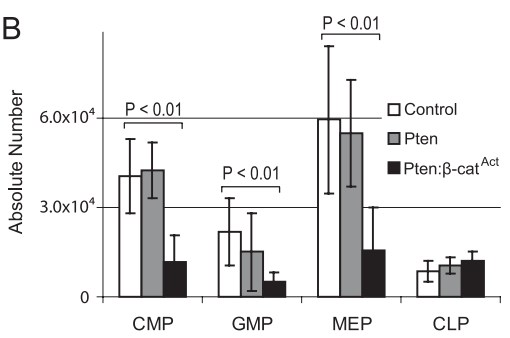

Figure 2. Impaired early myeloid differentiation in double mutants. (A) FACS diagrams with frequencies of early progenitors as indicated. $(B)$ Quantification of early BM progenitor cells in control, single mutants, and double mutants.

$(88 \% \pm 4 \%)$, we determined that most Pten mutant LSK Flk2 ${ }^{-}$cells had differentiated. In contrast, recipients of $\beta$-cat ${ }^{A c t}$-Z/EG LSK Flk2 ${ }^{-}$cells had essentially no donorderived $\left(\mathrm{EGFP}^{+}\right)$LSK Flk2 ${ }^{-}$cells $(1.6 \% \pm 0.9 \%)$. However, almost all LSK Flk2 ${ }^{-}$cells from Pten: $\beta$-cat ${ }^{A c t}-Z / E G$ transplant recipients were $\mathrm{EGFP}^{+}(90.0 \% \pm 4.0 \%)$ (Fig. $\left.3 \mathrm{~B}\right)$. These data demonstrate that, while $\beta$-cat ${ }^{A c t}$ mutant phenotypic HSCs are not maintained and Pten mutant phenotypic HSCs mainly differentiate, double mutant phenotypic HSCs, in contrast, are maintained in vivo in their undifferentiated state.

\section{Contribution of each pathway to phenotypic HSC expansion}

Previous studies using Mxl-Cre-mediated activation of $\beta$-catenin revealed a transient accumulation of phenotypic HSCs with functional failure (Kirstetter et al. 2006; Scheller et al. 2006). Using the HSPC-specific Scl-Cre system, which avoids stimulation with INF, we found that $\beta$-cat ${ }^{A c t}$ single mutants exhibited a reduced frequency of LSK cells in BM at 6 wpi (Fig. 1A); however, we did not observe any long-term defects in $\beta$-cat ${ }^{\text {Act }}$ single mutants. Genotyping revealed that, although activated $\beta$-catenin ( $\Delta$ Exon3) was present in whole BM at $2 \mathrm{wpi}$, the active allele was not present at 16 wpi (Fig. 3C). To determine deletion efficiency in HSCs, we genotyped colonies derived from individual LSK CD34- ${ }^{-}$cells (see the Materials and Methods). We found that Pten was deleted with high efficiency in both Pten single and double mutants; however, although the $\beta$-cat ${ }^{A c t}$ allele was also present in all double mutant LSK CD34- ${ }^{-}$cells tested, no LSK CD34- ${ }^{-}$cells from

$\beta$-cat ${ }^{A c t}$ mutants contained the activated ( $\Delta$ Exon3) allele at 12 dpi (Fig. 3D; Supplemental Fig. 1A,B). These results further demonstrate that $\beta$-cat ${ }^{A c t}$ single mutant HSCs were not maintained in vivo. Analysis of mature lineages in $\mathrm{BM}$ at 12 dpi revealed that the $\beta$-cat ${ }^{\text {Act }}$ allele was abundantly present in T cells and erythroid cells but was

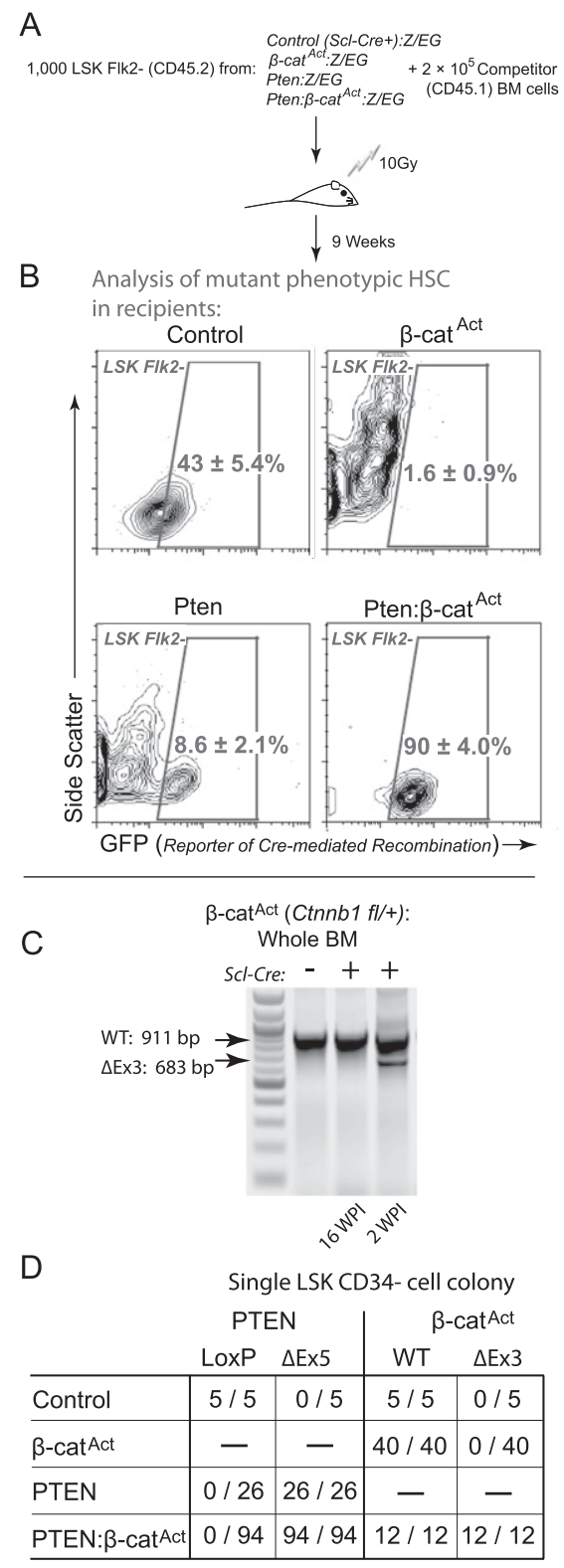

Figure 3. Maintenance of transplanted double mutant phenotypic HSCs in vivo. (A) Experiment design. Recipients were transplanted with 1000 LSK Flk2 ${ }^{-}$cells derived from control, single mutant, and double mutant donors $+2 \times 10^{6}$ rescue $\mathrm{BM}$ cells. (B) EGFP reporter expression in LSK Flk2- cells at 9 wpi from recipients as described in $A$, using the $Z / E G$ transgenic reporter construct to identify cells expressing mutant alleles. $(C)$ Whole BM from $\beta$-cat ${ }^{A c t}$ mutants at 16 and 2 wpi genotyped for deletion of Exon $3(\Delta \mathrm{Ex} 3)$. (D) Summary of genotyping results for single LSK CD34- cell colonies from control, single mutants, and double mutants (number of colonies positive for indicated band/total number tested). 
not found in myeloid cells or B cells (Supplemental Figure 1C). These data are consistent with differentiation blockage of myeloid and B-cell lineages.

Because we were unable to pinpoint the exact time when $\beta$-cat ${ }^{A c t}$ HSCs were lost in vivo, we observed $\beta$-cat ${ }^{A c t}$ HSCs in vitro by sorting phenotypic HSCs from uninduced $\beta$-cat ${ }^{A c t}$ mice, inducing genetic deletion in vitro with 4-hydroxy-tamoxifen (OHT), and then visually monitoring the cultures. At $48 \mathrm{~h}$ post-induction, we observed that $\beta$-cat ${ }^{A c t}$ LSK Flk2 ${ }^{-}$cultures contained fewer cells than control and generally had a less healthy appearance (Fig. 4A). We tested whether these cells were undergoing apoptosis by staining for Annexin V. Unlike control, the majority of $\beta$-cat ${ }^{A c t}$ LSK Flk2- cells at $48 \mathrm{~h}$ post-induction were either undergoing apoptosis or already dead, demonstrating that constitutive activation of $\beta$-catenin in LSK Flk2 ${ }^{-}$cells in vitro results in rapid apoptosis (Fig. 4B). By 4 dpi, no $\beta$-cat ${ }^{A c t}$ LSK Flk2 ${ }^{-}$cells survived; however, control, Pten, and particularly double mutant LSK Flk2 ${ }^{-}$cells survived and expanded (Fig. 4C). LSK Flk2 ${ }^{-}$cells from wildtype Scl-Cre-positive mice were not significantly different from Scl-Cre-negative controls, demonstrating that the survival defect in $\beta$-cat ${ }^{A c t}$ mutant HSCs is not due to any potential Cre toxicity (data not shown). These data demonstrate that $\beta$-cat ${ }^{A c t}$ mutant HSCs have a survival defect. Furthermore, this survival defect can be rescued by additional loss of Pten.
In contrast, we found that Pten single mutants exhibited increases in both the frequency and absolute number of LSK CD34- cells in the spleen at 6 wpi (Fig. 1B,E), although these changes are not nearly as large as those observed in double mutants. At 9-10 wpi, early myeloid progenitors were substantially increased in BM and especially the spleen of Pten single mutants (Fig. 4D), as were more mature myeloid cells (data not shown). These data demonstrate that loss of Pten in our mouse model leads to more moderate but sustained mobilization and expansion of phenotypic HSCs than in double mutants; however, in contrast to double mutants, this is accompanied by increased myeloid differentiation.

To study more comprehensively the role of $\beta$-catenin interaction with the PTEN/Akt signaling pathway, we obtained mice with floxed null alleles of $\beta$-catenin (Ctnnb1 $\left.{ }^{\text {tm2Kem}}\right)$ (Cobas et al. 2004) and crossed them to Pten mutants, allowing conditional deletion of $\beta$-catenin $\left(\beta-\right.$ cat $\left.^{-/-}\right)$, Pten, or Pten: $\beta$-cat ${ }^{-/-}$combined. Consistent with results in previous studies, $\beta$-cat ${ }^{-/-}$single mutant recipients did not exhibit any defects in absolute numbers of LSK or early progenitors (Cobas et al. 2004). Interestingly, Pten: $\beta$-cat ${ }^{-1-}$ double knockouts did not exhibit an expansion of LSK cells in the spleen or BM, and CMPs as well as MEPs were substantially reduced compared with Pten single mutants (Fig. 4E; data not shown). These results further confirm that the Wnt/ $\beta$-catenin and PTEN/Akt
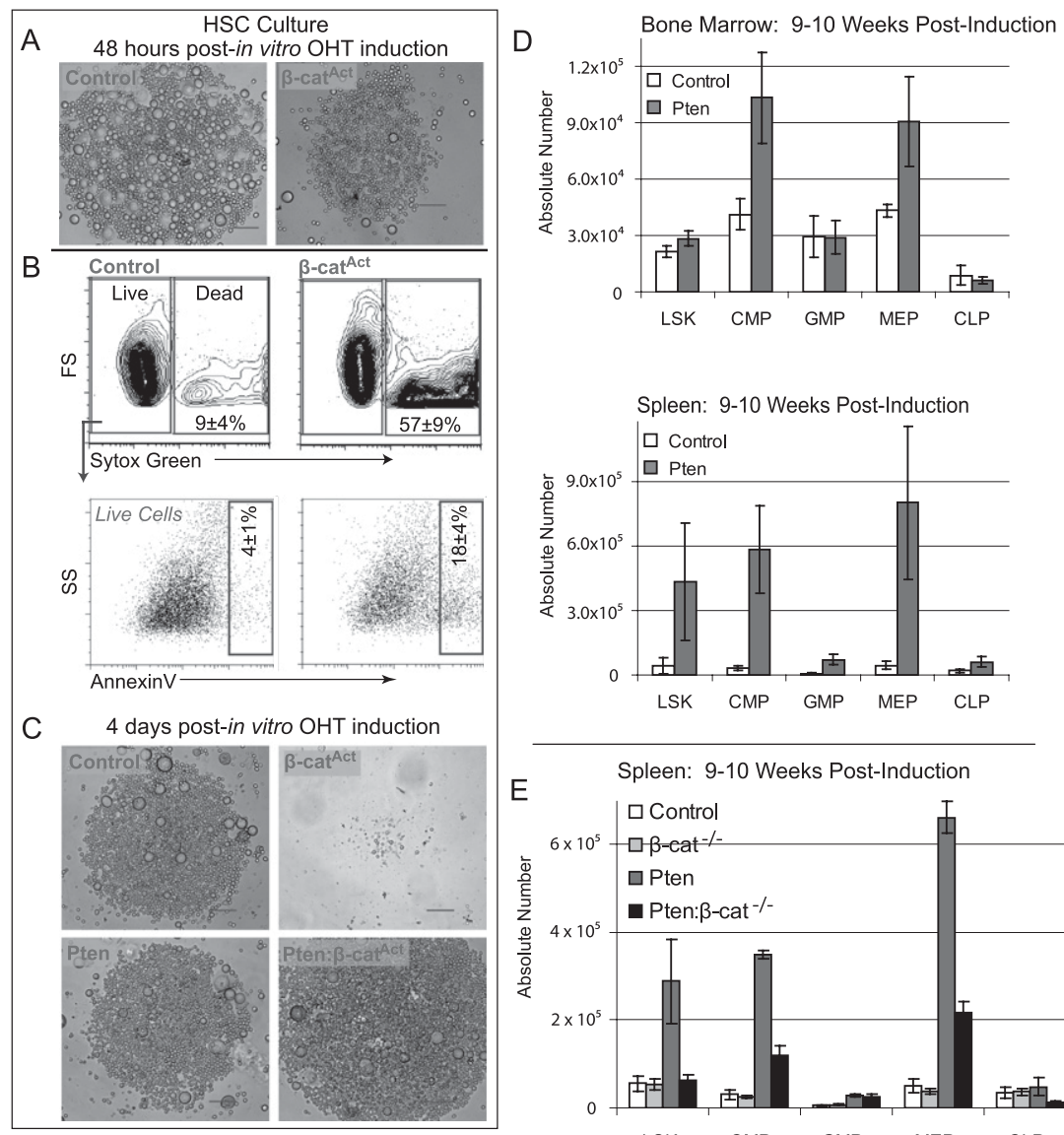

Figure 4. Functional contribution of each pathway to survival and differentiation. $(A)$ One-thousand LSK Flk2- cells were sorted per well from BM isolated from uninduced control, Pten, $\beta$-cat ${ }^{A c t}$, and Pten: $\beta$-cat ${ }^{\text {Act }}$ mice and cultured in ST medium (see the Materials and Methods). Within $12 \mathrm{~h}$ of sorting, OHT was added to the cultures for a final concentration of $1 \mu \mathrm{M}$. Cultures are depicted at $48 \mathrm{~h}$ after in vitro induction. $(B)$ Cultures from $A$ were stained with Sytox Green and Annexin V and analyzed by FACS. Representative FACS plots distinguishing live (Sytox Green-negative) from dead (Sytox Green-positive) cells. Live cells were further gated for Annexin V-positive (apoptotic) cells. Numbers within gates represent the mean \pm SD from three independent experiments. $(C)$ Cultures are as described in $A$ at 4 dpi. $(D)$ Absolute number of LSK cells and early hematopoietic progenitors in control and Pten mutant BM (tibia and femur) and spleen as determined by FACS analysis at 9-10 wpi. (E) Absolute number of LSK cells and early progenitors in the spleen as determined by FACS analysis on mice transplanted with control, $\beta$-cat ${ }^{-/-}$, Pten, and Pten: $\beta$-cat ${ }^{-/-}$ $\mathrm{BM}$ as indicated; analysis is at $9-10 \mathrm{wpi}$.

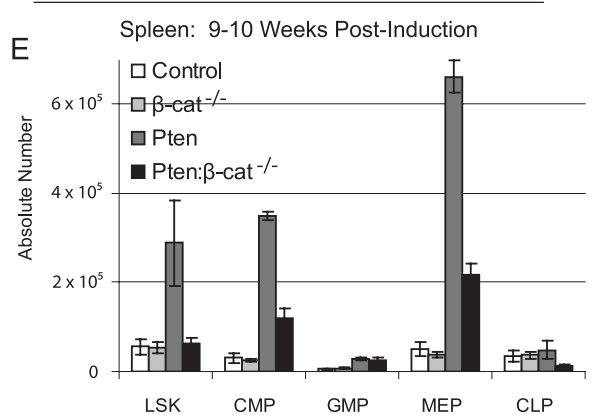


pathways cooperatively interact in driving phenotypic HSC expansion. Specifically, loss of $\beta$-catenin prevents the LSK cell expansion resulting from Pten deletion, which shows that the PI3K/Akt-mediated expansion is dependent on $\beta$-catenin and further confirms that $\beta$-catenin impairs myeloid differentiation.

Akt activates $\beta$-catenin by phosphorylation of serine residue 552 (S552) (He et al. 2007). Our laboratory developed an antibody highly specific for $\beta$-catenin phosphorylated at S552 ( $\beta$-cat-pS552), which reveals simultaneous activation of the two pathways (He et al. 2007). We hypothesized that $\beta$-cat-pS552 antibody may also recognize activated HSCs. To investigate this, we transplanted sorted LSK Flk2 ${ }^{-}$ cells that express green fluorescent protein (GFP ${ }^{+}$HSCs) into irradiated and nonirradiated mice, sacrificed recipients, and stained bone sections with anti- $\beta$-cat-pS552 antibody. With irradiation, a condition previously shown to result in rapid HSC expansion (Xie et al. 2009), we were able to visualize $\mathrm{GFP}^{+}$-HSCs adjacent to their endosteal niche, with five of $40 \mathrm{GFP}^{+}$HSCs costaining as $\beta$-cat-pS552 $2^{+}$ cells and in the process of active division (Supplemental Fig. 2). However, without irradiation, a condition where HSCs do not expand (Xie et al. 2009), no GFP ${ }^{+}$HSCs were found to be $\beta$-cat-pS552 $2^{+}$. These results support the importance of activated Akt/ $\beta$-catenin interaction in normal but proliferating HSCs.

\section{Underlying genetic mechanism of phenotypic HSC expansion}

We sought to further elucidate the mechanism underlying each pathway's individual and combined contribution to HSC regulation in our mouse models. Multiple transcription factors required for lineage differentiation are expressed at low levels in HSCs. This promiscuous expression has been referred to as lineage priming and indicates that HSC differentiation depends largely on extinguishing alternate possibilities rather than on instructing a naive cell (Hu et al. 1997; Enver and Greaves 1998; Miyamoto et al. 2002; Akashi et al. 2003; Orkin and Zon 2008). We investigated this phenomenon in double mutant phenotypic HSCs by quantitative RT-PCR (qRT-PCR). While Pten single mutant LSK Flk2 $2^{-}$cells expressed a higher level of multiple transcription factors than control, double mutant LSK Flk2 ${ }^{-}$cells had significantly reduced expression of lineage-priming factors, including $C / E B P \alpha$, GATA1, GATA3, and PU.1 (Fig. 5A). Combined with our in vivo experiments, these data demonstrate that, while lineage priming in Pten mutant HSCs increases differentiation, reduced expression of multiple differentiation factors in double mutants provides an explanation for the broad impairment of differentiation in double mutant phenotypic HSCs. In addition, HoxB4 has been shown to be a strong positive regulator of HSC self-renewal (Sauvageau et al. 1995; Antonchuk et al. 2002; Reya et al. 2003), and we found that HoxB4 was highly expressed in Pten: $\beta$-cat ${ }^{\text {Act }}$ LSK Flk2 ${ }^{-}$cells compared with control and Pten single mutants (Fig. 5A).

We also performed microarray analyses on sorted LSK Flk2 ${ }^{-}$cells. Because $\beta$-cat ${ }^{A c t}$ single mutant HSCs have
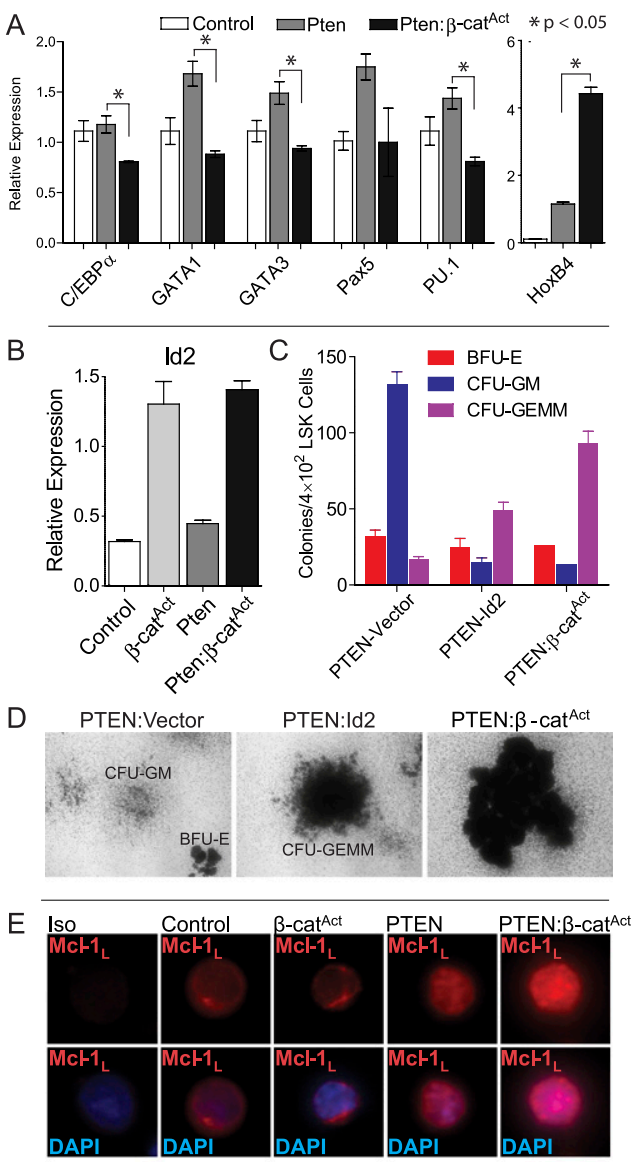

F

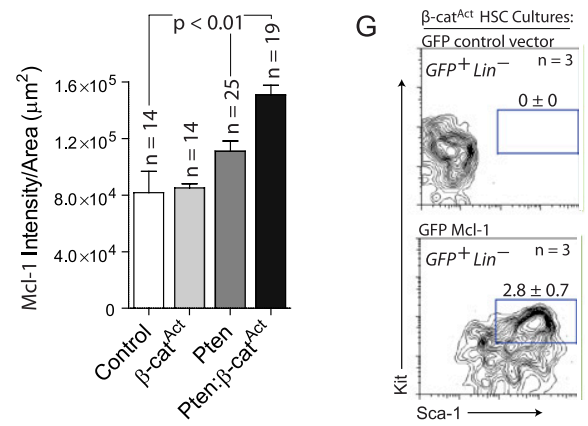

Figure 5. Mechanistic contribution to self-renewal provided by both pathways. $(A, B)$ qRT-PCR for indicated lineage-priming genes, HoxB4, and Id2 on control, single mutant, and double mutant LSK CD34- cells. $(C)$ CFU assays on EGFP ${ }^{+}$LSK cells sorted from Pten BM cultures transduced with EGFP-vector control or EGFPId2 compared with LSK cells sorted from double mutant cultures. $(D)$ Representative images of CFU colonies described in $C$. $(E)$ Representative immunostaining of LSK cells sorted from control, single mutants, and double mutants for $\mathrm{Mcl}^{-1_{\mathrm{L}}}$. $(F)$ Quantification of $\mathrm{Mcl}-1_{\mathrm{L}}$ staining intensity of LSK cells from control, single mutants, and double mutants. $(G)$ BM cells from uninduced $\beta$-cat ${ }^{A c t}$ mutants were transduced with EGFP-vector control or EGFP-Mcl-1. Following transduction, cultures were induced with OHT. FACS analysis at $11 \mathrm{dpi}$ for EGFP ${ }^{+}$LSK cells from $\beta$-cat ${ }^{\text {Act }}$ cultures transduced with EGFP-vector control or EGFP-Mcl-1.

a survival defect, we took advantage of our in vitro culture system to obtain enough cells for microarray analysis. BM mononuclear cells (MNCs) were cultured for $12 \mathrm{~d}$ 
in medium supporting HSC expansion (see below), Cre was induced by addition of OHT, and LSK Flk2 ${ }^{-}$cells were sorted from these cultures $48 \mathrm{~h}$ post-induction. We identified differentially expressed genes in double and single mutants relative to control and each other (Supplemental Table 1). Cluster analysis revealed that, overall, most variation occurred in $\beta$-cat ${ }^{\text {Act }}$ single mutant LSK Flk2 ${ }^{-}$ cells, with Pten and Pten: $\beta$-cat ${ }^{\text {Act }}$ being more similar to each other as well as control LSK Flk2- cells (Supplemental Fig. 3). Literature review identified candidate genes for qRT-PCR verification. Inhibitor of differentiation 2 (Id2) inhibits myeloid and B-cell differentiation and is highly expressed in HSCs with decreasing expression with differentiation (Ji et al. 2008; Doulatov et al. 2009; Li et al. 2010). Interestingly, qRT-PCR verification revealed Id2 expressed higher in $\beta$-cat ${ }^{\text {Act }}$ and Pten: $\beta$-cat ${ }^{A c t}$ relative to control and Pten LSK Flk2 $2^{-}$cells (Fig. 5B). Thus, upregulation of $I d 2$ resulting from $\beta$-catenin activation may provide a mechanism, at least in part, to explain the impaired differentiation observed in double mutants. To test this, we transduced Pten mutant BM cells with lentivirus expressing Id2-EGFP or EGFP-vector control. To test whether Id2 affected the differentiation capacity of HSPCs, we sorted EGFP ${ }^{+}$LSK cells from Id2 and vector control transduced cultures into methylcellulose medium and performed colony-forming unit (CFU) assays. Pten LSK cells transduced with vector control mainly formed more mature CFU-GM (granulocyte/monocyte) colonies, as expected; however, Pten LSK cells transduced with Id2 predominantly formed large, immature CFUGEMM/granulocyte/erythrocyte/monocyte/megakaryocyte) colonies. Interestingly, this phenocopied the CFU formation from double mutant LSK cells, which also predominantly formed large, primitive CFUs (Fig. 5C,D). These data demonstrate that activated $\beta$-catenin increases Id2 expression, which functionally inhibits myeloid differentiation.

$\beta$-cat ${ }^{A c t}$ phenotypic HSCs have a survival defect that is rescued by additional deletion of Pten (Figs. 3A-D, 4A-C; Supplemental Fig. 1). Our culture method combined with only brief induction via OHT in vitro allowed us to obtain the $>3 \times 10^{4} \beta$-cat ${ }^{A c t}$ mutant phenotypic HSCs necessary for microarray analysis; however, it also likely obscured the cause of the survival defect in $\beta$-cat ${ }^{\text {Act }}$ mutant phenotypic HSCs. To investigate the molecular link resulting in apoptosis of $\beta$-cat ${ }^{A c t}$ HSCs, we examined expression of the Bcl-2 family member Mcl-1. Mcl-1 has an obligate role in survival of HSCs, making it a candidate for preventing apoptosis of double mutant phenotypic HSCs (Opferman et al. 2005). LSK cells were sorted from control, single mutants, and double mutants and immunostained for the anti-apoptotic long form of Mcl-1 (Mcl$1_{\mathrm{L}}$ ). Mcl-1 $1_{\mathrm{L}}$ was more abundant in the nucleus of Pten mutant LSK cells compared with control and $\beta$-cat ${ }^{A c t}$ mutant LSK cells. Quantification of staining intensity revealed that double mutants had even more abundant nuclear Mcl-1 $\mathrm{L}_{\mathrm{L}}$ than did Pten single mutants (Fig. 5E,F). These data indicate that $\mathrm{Mcl}-1_{\mathrm{L}}$ provides the mechanistic link for preventing apoptosis of HSCs in double mutants.
To prove that Mcl-1 could rescue the survival defect of $\beta$-cat ${ }^{A c t}$ mutant phenotypic HSCs, we transduced $\beta$-cat ${ }^{A c t}$ $\mathrm{BM}$ cells with lentivirus expressing Mcl-1-EGFP or EGFPvector control. Following in vitro induction with $\mathrm{OHT}$, $\mathrm{BM}$ cultures were monitored for the presence of $\mathrm{EGFP}^{+}$ LSK cells. At $11 \mathrm{dpi}$, no LSK cells were present in $\beta$-cat ${ }^{A c t}$ mutant cultures transduced with vector control; however, cultures transduced with Mcl-1 maintained a population of LSK cells (Fig. 5G). These data demonstrate that $\mathrm{Mcl}-1$ rescues the survival defect resulting from activation of $\beta$-catenin.

\section{In vitro expansion of double mutant LSK cells}

We tested the ability of control, single mutant, and double mutant LSK cells to expand in vitro. LSK cells were sorted from control, single mutant, and double mutant BM and cultured in serum-free medium based on a previous report regarding ex vivo HSC expansion (Zhang and Lodish 2005). After $10 \mathrm{~d}$ of culture, control LSK cells had undergone a modest expansion, while $\beta$-cat ${ }^{\text {Act }}$ cultures, again, did not survive. Pten LSK cultures expanded to a greater degree than control, but the greatest expansion was observed in double mutant cultures (Fig. 6A). Pten and Pten: $\beta$-cat ${ }^{A c t}$ cultures continued to expand up to $5 \mathrm{wk}$ in vitro; however, control cultures began to decline after 4 wk (data not shown). Unlike control, both Pten and Pten: $\beta$-cat ${ }^{\text {Act }}$ cultures remained robust after $5 \mathrm{wk}$, but Pten: $\beta$-cat ${ }^{A c t}$ cultures contained far more cells and their appearance was more homogenous than Pten cultures (Fig. 6B). At 7 wk, we reanalyzed a portion of the remaining Pten and Pten: $\beta$-cat ${ }^{\text {Act }}$ cultures to determine how many cells maintained the LSK phenotype (Fig. 6C). Due to long-term culture, these cells expressed unusually high levels of Kit and Sca-1. While LSK cells from Pten cultures had expanded 50-fold, Pten: $\beta$-cat ${ }^{\text {Act }}$ cultures had expanded $>1200$-fold (Fig. 6D). In addition, the percentage of total cells that maintained the LSK phenotype was significantly higher in Pten: $\beta$-cat ${ }^{A c t}$ cultures than in Pten-only cultures (Fig. 6D). These data demonstrate that double mutant LSK cells can expand longterm in vitro to a greater degree than control or single mutants.

Ex vivo expansion of functional, long-term reconstituting HSCs by simultaneous activation of PI3K and $\beta$-catenin signaling

Double mutants exhibit an expansion of phenotypic, yet functionally compromised, HSCs. We sought to develop an in vitro expansion protocol for normal HSCs that would avoid both genetic manipulation and functional impairment. Reversible, pharmacological manipulation of the PTEN/Akt and Wnt/ $\beta$-catenin pathways may allow for the transient enhancement of HSC expansion in vitro without compromising the capacity to function as normal HSCs after the pharmacological agents are removed and the HSCs are then transplanted in vivo.

We established a serum-free culture system using only low doses of two cytokines: stem cell factor (SCF) and 

A 10 day culture: 100 Sorted LSK Cells
Control $\quad \beta$-cat

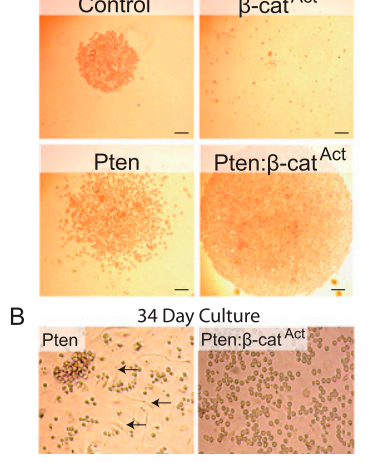

C
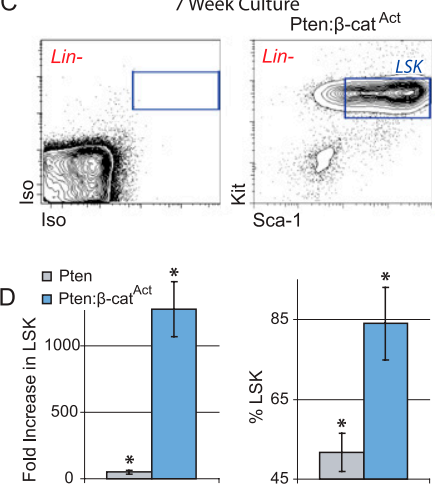

E Base Media +CHIR99021 +Insulin +CHIR99021

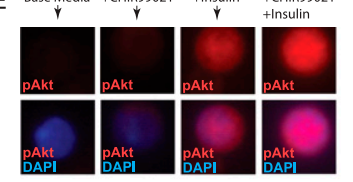

$\mathrm{F}$
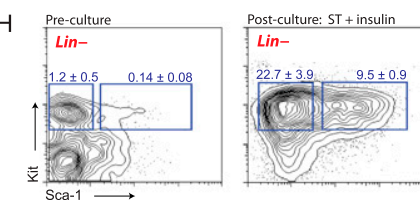

(1)
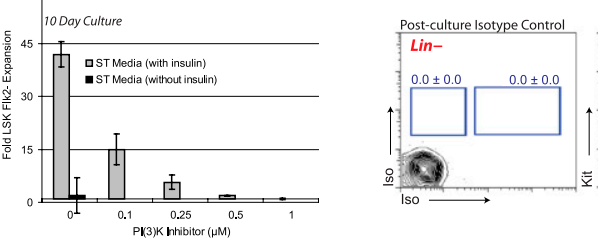

Post-culture: ST + insulin Post-culture: ST T insulin
+ GSK33 inhibititor Lin-
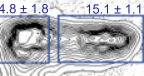
12
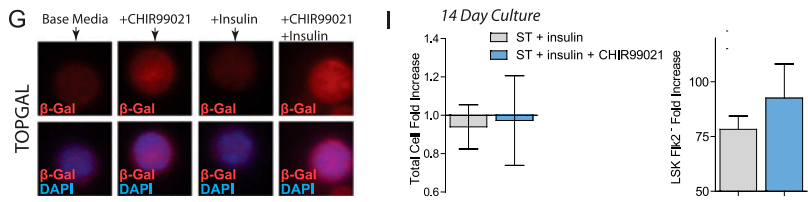

Figure 6. Simultaneous activation of PI3K and $\beta$-catenin signaling increases phenotypic HSC expansion in vitro. (A) Onehundred LSK cells sorted from control, $\beta$-cat ${ }^{A c t}$, Pten, and Pten: $\beta$-cat ${ }^{\text {Act }}$ mice and cultured for $10 \mathrm{~d}$. (B) LSK cells from Pten and Pten: $\beta$-cat ${ }^{A c t}$ mutants at $34 \mathrm{~d}$ of culture. Control cultures do not expand beyond $4 \mathrm{wk} ; \beta$-cat ${ }^{A c t}$ mutant cultures do not survive beyond $10 \mathrm{~d}$. Note the greater degree of differentiation, including adherent cells in Pten cultures (arrows). $(C, D)$ At 7 wk of culture, cells from Pten and Pten: $\beta$-cat ${ }^{A c t}$ LSK cultures were counted and analyzed by FACS for maintenance of the LSK phenotype. $(C)$ FACS diagram of 7 -wk-cultured Pten: $\beta$-cat ${ }^{A c t}$ LSK cells (pregated on live, Lin $^{-}$cells) along with isotype control. $(D)$ Total fold increase in LSK cells and percent maintaining LSK phenotype after $7 \mathrm{wk}$ of culture. (E) MNCs were cultured for $7 \mathrm{~d}$ in base medium and base medium + CHIR99021 and/or insulin as indicated. LSK Flk2 ${ }^{-}$cells were sorted from these cultures and stained for phosphor-Akt Ser 473 (pAkt). (F) BM MNCs from C57BL/6 mice were cultured for $10 \mathrm{~d}$ in ST \pm insulin medium along with the indicated concentrations of PI3K inhibitor (NVPBEZ235) and then analyzed by FACS to determine expansion of LSK Flk2 ${ }^{-}$cells. $(G)$ MNCs isolated from TOPGAL mice were cultured for $7 \mathrm{~d}$ in base medium and base medium + CHIR99021 and/or insulin as indicated. LSK Flk2 ${ }^{-}$cells were sorted from these cultures and stained for $\beta$-galactosidase $(\beta$-Gal). (H) FACS diagrams (pregated Lin ${ }^{-}$cells) showing preculture and 14-d postculture analysis of LSK and early progenitor cells with and without addition of lithium. Frequency of early myeloid (left, blue box) and LSK (right, blue box) per total, live cells is shown \pm SD. (I) Quantification of total cell and LSK Flk2 ${ }^{-}$cell expansion after 14-d culture of MNCs in ST + insulin medium with and without 250 nM CHIR99021. thrombopoietin (Tpo) (ST medium) (see the Materials and Methods; Zhang and Lodish 2005). We found that the optimal base medium for expanding phenotypic HSCs (StemSpan SFEM, Stem Cell Technologies, Inc.) contains a high concentration of insulin, a major stimulator of the PI3K/Akt pathway. We verified that addition of insulin activated the PI3K/Akt pathway in our ex vivo system by sorting LSK Flk2- cells cultured with and without insulin and then immunostaining for phospho-Akt (Ser 473). Insulin was shown to increase phospho-Akt in phenotypic HSCs using our culture system (Fig. 6E). Because base medium without insulin was unable to substantially expand HSCs, expansion of phenotypic HSCs was dependent on insulin in our culture system (Fig. 6F). Also, addition of a small molecule inhibitor of PI3K (NVP-BEZ235) (Maira et al. 2008) decreased the ability of LSK Flk2 ${ }^{-}$cells to expand in a dose-dependent manner (Fig. 6F). Together, these data demonstrate that stimulation of PI3K signaling is required for substantial HSC expansion in our culture system.

GSK3 $\beta$ normally inhibits $\beta$-catenin by targeting it for proteasomal degradation. Pharmacological activation of $\beta$-catenin can be accomplished by inhibition of GSK3 $\beta$ (Sato et al. 2004). We first verified that GSK3 $\beta$ inhibition activated Wnt signaling by using TOPGAL reporter mice. We sorted LSK Flk2- cells from TOPGAL MNCs cultured with and without the GSK3 $\beta$ inhibitor CHIR99021 and immunostained for $\beta$-galactosidase. CHIR99021 was shown to increase $\beta$-galactosidase in phenotypic HSCs in our culture system, indicating increased Wnt pathway activation (Fig. 6G). We also found that increasing concentrations of GSK3 $\beta$ inhibitor resulted in increasing proportions of LSK cells relative to early myeloid progenitors. Specifically, without GSK3 $\beta$ inhibition, the frequency of early myeloid progenitors was more than twice as high as that of LSK cells. However, addition of GSK3 $\beta$ inhibitor decreased the frequency of myeloid progenitors but increased the frequency of LSK cells, yielding equivalent frequencies of early myeloid and LSK cells (Fig. 6H). Although the preculture frequency of LSK cells was only $0.14 \% \pm$ $0.08 \%$ in BM MNCs, this increased to $9.5 \% \pm 0.9 \%$ after $14 \mathrm{~d}$ of culture in ST medium and further increased to $15.1 \% \pm 1.1 \%$ with GSK3 $\beta$ inhibitor addition. Although the total number of cells after culture was not increased, the total number of LSK Flk2 ${ }^{-}$cells increased 78 -fold without GSK3 $\beta$ inhibitor and 93-fold with GSK3 $\beta$ inhibitor addition (Fig. 6I). Interestingly, these data partially mimic our genetic mutant animal models.

To determine whether our culture method expands not only phenotypic but also functional HSCs, we performed in vivo transplantation assays. Sorted LSK Flk2 $2^{-}$cells were cultured for $14 \mathrm{~d}$ in medium with factors stimulating PI3K signaling (ST + insulin) or in medium stimulating both PI3K and $\beta$-catenin signaling (ST + insulin + CHIR99021). The progeny of 100 LSK Flk2 $2^{-}$cells along with $1 \times 10^{5}$ competitor cells were then transplanted into lethally irradiated recipients. Donor-derived, long-term, multilineage reconstitution was exhibited by all recipients from both groups; however, the average percentage of donorderived cells was substantially greater when cultured 
with CHIR99021 than without (12.3\% vs. $1.1 \%$, respectively) (Fig. 7A). This demonstrated that addition of CHIR99021 enhanced repopulation capacity of cultured cells originating from enriched HSCs. We tested our updated protocol (see the Materials and Methods; Fig. 6H,I) using MNCs with a known quantity of LSK Flk2 ${ }^{-}$cells, since this provided the most robust HSC expansion. We transplanted the cultured progeny of MNCs initially containing five LSK Flk2 ${ }^{-}$cells (unsorted) along with $1 \times 10^{5}$ competitor cells into lethally irradiated recipients. For comparison, we transplanted freshly isolated, uncultured MNCs containing five LSK Flk2 ${ }^{-}$cells along with $1 \times 10^{5}$ competitor cells into a separate lethally irradiated group. Again, addition of CHIR99021 to the unsorted cultures significantly increased donor reconstitution $(64.8 \%$ vs. $37.4 \%$ without CHIR99021). Notably, all recipients of freshly isolated, uncultured MNCs containing five LSK Flk2 ${ }^{-}$cells exhibited little or no repopulation $(0.6 \% \pm 0.5 \%)$, demonstrating that our culture protocol substantially expands functional HSCs (Fig. 7A).

To quantify the number of functional HSC resulting from our culture system, we performed limiting dilution, competitive repopulating unit (CRU) assays (Miller and Eaves 1997; CC Zhang et al. 2006). Poisson statistical analysis of $n=60$ total recipient mice showed that the cultured progeny contained a frequency of one CRU per two input (preculture) LSK Flk2 ${ }^{-}$cells $(1 / 2 ; 95 \%$ confidence interval: $1 / 1$ to $1 / 5$ ) for $S T+$ insulin medium conditions, but when CHIR99021 was added, the frequency was $1 / 0.4(95 \%$ confidence interval: $1 / 0.2$ to $1 / 0.8$ ) (Fig. $7 \mathrm{~B}$ ). Thus, addition of CHIR99021 increases the CRU frequency by an average of fivefold $(2 / 0.4)$.

More mature radioprotective cells are necessary for shortterm survival of recipients transplanted with purified HSCs, and early myeloid progenitors have been found to confer this radioprotective effect (Na Nakorn et al. 2002). Considering the high frequency of progenitor cells present in our cultures (Fig. 6H), we hypothesized that our culture system might expand radioprotective cells as well, eliminating the need for fresh, whole BM rescue cells. To test this, after culture in ST + insulin medium with and without CHIR99021, we transplanted only the cultured progeny of MNCs initially containing five LSK Flk $2^{-}$cells into lethally irradiated recipients. For comparison, we transplanted fresh, uncultured MNCs containing five LSK Flk2 ${ }^{-}$ cells into a separate group. For further comparison, since our culture system could achieve an $\sim 100$-fold increase in LSK Flk ${ }^{-}$cells (Fig. 6I), we also transplanted fresh, uncultured MNCs containing 500 LSK Flk2- cells (100× uncultured cells) into lethally irradiated recipients. No rescue cells were added in these groups. While recipients of uncultured MNCs containing five LSK Flk2 ${ }^{-}$cells had to be sacrificed due to BM failure between 2-3 wpi, mice transplanted with the cultured progeny of MNCs initially containing five LSK Flk2 ${ }^{-}$cells or fresh MNCs containing 500 LSK Flk2 $2^{-}$cells survived long-term. At 16 wpi, these recipients exhibited robust, multilineage donor repopulation with no significant difference between groups (Fig. 7C). To determine the long-term, functional capacity of our ex vivo expanded cells, we euthanized the primary $\left(1^{\circ}\right)$ recipients and performed serial BM transplantation into secondary $\left(2^{\circ}\right)$ recipients. At $16 \mathrm{wk}, 2^{\circ}$ transplant recipients of cells cultured in ST + insulin medium exhibited reduced average repopulation compared with $2^{\circ}$ recipients of cells cultured in ST + insulin + CHIR99021 or $100 \times$ uncultured cells. BM cells from these $2^{\circ}$ recipients were then transplanted into tertiary $\left(3^{\circ}\right)$ recipients. At $16 \mathrm{wk}$, average repopulation of $3^{\circ}$ recipients of cells cultured in ST + insulin medium was again further reduced relative to recipients of cells cultured with ST + insulin + CHIR99021 or 100 $\times$ uncultured cells. Notably, $3^{\circ}$ recipients of cells cultured with $\mathrm{ST}+$ insulin + CHIR99021 or $100 \times$ uncultured cells exhibited equivalent levels of repopulation with no statistical difference between the two groups $(P=0.9)$ (Fig. 7C).

While $3^{\circ}$ recipients of cells cultured in ST + insulin medium all succumbed to BM failure by 6 mo post-transplantation, recipients of cells cultured with ST + insulin + CHIR99021 exhibited survival rates similar to $3^{\circ}$ recipients of 100 $\times$ uncultured cells (Fig. 7D). Importantly, even those mice euthanized due to poor health did not exhibit signs of leukemia, but rather succumbed to BM failure, exhibiting low overall blood cell counts (data not shown). These data demonstrate that our culture protocol expands functional, long-term repopulating HSCs. Interestingly, pharmacological activation of both pathways $(\mathrm{ST}+$ insulin + CHIR99021 medium) increases long-term functional capacity following serial transplantation, demonstrating that activation of both pathways is important, particularly for LT-HSC potential.

\section{Discussion}

Transduction of HSCs with a constitutively active $\beta$-catenin has been shown to promote impressive expansion of HSCs in culture (Reya et al. 2003). However, substantial expansion was obtained only when using Bcl-2 transgenic mice, and later studies reported conflicting results (Nemeth et al. 2007; Malhotra and Kincade 2009). Interestingly, Bcl-2 inhibits apoptosis. In particular, only short-term (4- to 8-wk) repopulation was reported using HSCs from normal mice cultured with Wnt3A (Reya et al. 2003; Willert et al. 2003). Subsequent studies reported that noncanonical Wnt5a inhibited canonical Wnt3a-mediated signaling to promote the maintenance of quiescent, functionally transplantable HSCs. Our study helps resolve these issues and sheds light on these and other previous findings.

Previous studies using Mxl-Cre have shown that in vivo activation of $\beta$-catenin resulted in failure of functional HSCs due to impaired differentiation and HSC exhaustion due to cycling (Kirstetter et al. 2006; Scheller et al. 2006). This functional loss was coupled with decreased expression of HSC regulators, including HoxB4 (Kirstetter et al. 2006). By switching to HSPC-specific conditional mutants that avoid INF activation of HSCs, we were able to study defects arising primarily from HSCs and perform long-term studies of double mutant HSCs in vivo. This more refined model using Scl-Cre also revealed that activation of $\beta$-catenin results in differentiation blockage and HSC failure; however, we also found 

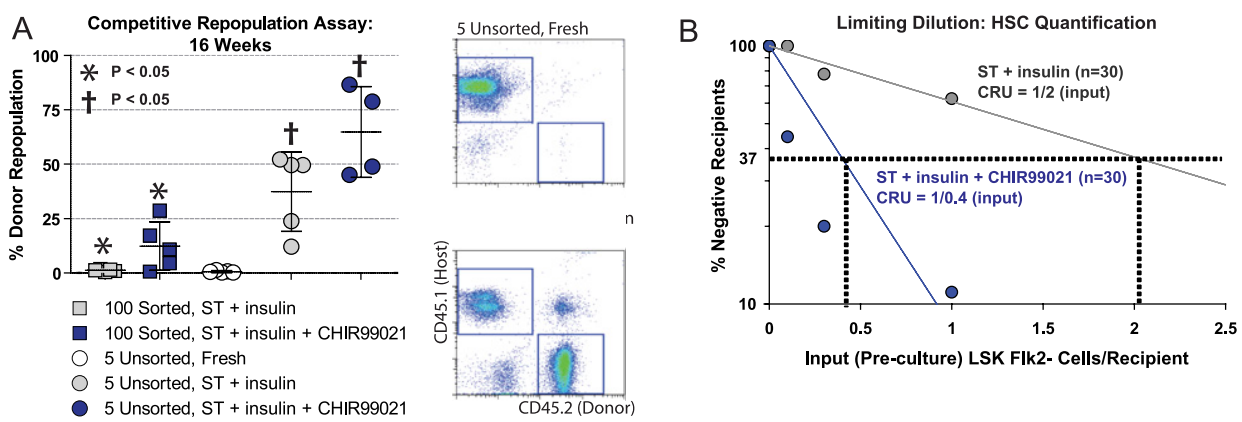

C Non-competitive Serial Transplantation
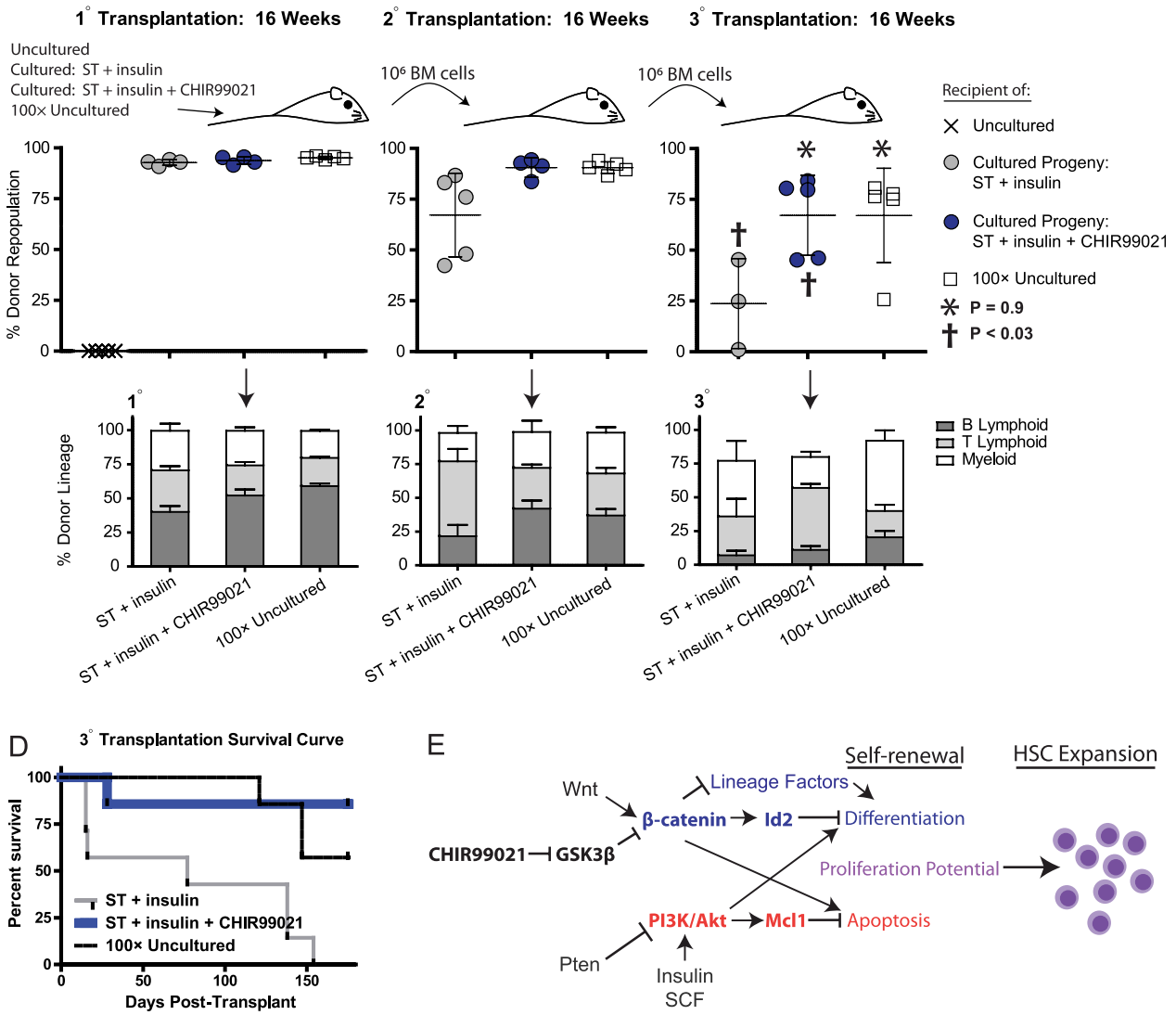

Figure 7. Functional, long-term repopulating HSCs expanded ex vivo by simultaneous activation of PI3K and $\beta$-catenin pathways. $(A)$ Sorted LSK Flk2 $2^{-}$cells and unsorted MNCs containing a known quantity of LSK Flk2 ${ }^{-}$cells $\left(\mathrm{CD} 45.2^{+}\right)$were cultured for $14 \mathrm{~d}$ in ST + insulin medium with and without CHIR99021. The cultured progeny of 100 sorted or five unsorted LSK Flk2- cells along with $1 \times 10^{5}$ freshly isolated CD 45. $1^{+}$competitor/rescue cells per mouse were transplanted into lethally irradiated recipients $\left(\mathrm{CD} 45.1^{+}\right)$. Five freshly isolated, unsorted LSK Flk2 $2^{-}$cells along with $1 \times 10^{5}$ competitor/rescue cells per mouse were transplanted into a separate group. Peripheral blood of recipients was analyzed at $16 \mathrm{wk}$ post-transplant. (Right) Representative FACS plots depicts percent chimerism. $(B)$ MNCs containing a known quantity of LSK Flk2 $2^{-}$cells were cultured for $14 \mathrm{~d}$ in ST + insulin medium with and without CHIR99021. The cultured progeny of MNCs initially containing a preculture dosage of $0.1,0.3$, or 1.0 LSK Flk2- cells were transplanted into lethally irradiated recipients along with $1 \times 10^{5}$ rescue/competitor cells $(n=10$ for each of six groups). Peripheral blood was analyzed at 16 wk post-transplant, and CRU frequency was determined using L-Calc software (Stem Cell Technologies, Inc.) based on Poisson statistics (Miller and Eaves 1997). (C) Fresh MNCs containing five or 500 LSK Flk2 ${ }^{-}$cells, or the progeny of MNCs initially containing five LSK Flk2 ${ }^{-}$cells cultured for $14 \mathrm{~d}$ in ST + insulin medium with and without CHIR90921, were transplanted into lethally irradiated recipients without rescue/competitor cells. At $16-17$ wk post-transplant, BM isolated from $1^{\circ}$ recipients was transplanted into $2^{\circ}$ recipients and, at $16-17$ wk after $2^{\circ}$ transplant, from $2^{\circ}$ into $3^{\circ}$ recipients at a dosage of $1 \times 10^{6}$ cells per mouse. Peripheral blood was analyzed for percent donor repopulation at $16 \mathrm{wk}$ after $1^{\circ}, 2^{\circ}$, and $3^{\circ}$ transplant (top panels) and for percent mature donor-derived $\mathrm{B}, \mathrm{T}$, and myeloid cells (bottom panels). (D) Kaplan-Meier survival curve for $3^{\circ}$ transplant recipients from $C$. (E) Model illustrating individual and combined effects of Wnt/ $\beta$-catenin and PTEN/Akt signaling pathway activation driving HSC expansion. 
that $\beta$-cat ${ }^{\text {Act }}$ mutant phenotypic HSCs exhibit a survival defect that can be rescued by deletion of Pten. Notably, phenotypic LT-HSC expansion is particularly dramatic in Scl-Cre double mutants. Unlike previous studies on $\beta$-cat ${ }^{A c t}$ single mutants using Mxl-Cre, phenotypic LT-HSCsrather than short-term or multipotent progenitorspredominantly expanded, and HoxB4 expression increased in phenotypic HSCs in our double mutant animal model. Recent studies have shown that INF also increases phosphorylation of Akt (Essers et al. 2009). Thus, stimulation by INF may allow for more prolonged survival of $\beta$-cat ${ }^{A c t}$ mutant phenotypic HSCs in the Mx1-Cre system (Kirstetter et al. 2006; Scheller et al. 2006). Also, previous studies on Pten deletion using the Mx1-Cre system revealed rapid development of MPD and HSC exhaustion following transient expansion (Yilmaz et al. 2006; J Zhang et al. 2006). In the Scl-Cre system, HSC expansion is moderate but sustained and coupled with increased myeloid differentiation; however, most Scl-Cre Pten single mutants survive for at least 4 mo post-induction. It may be that INF stimulation when using the Mx1-Cre system results in synergistic effects between INF signaling (particularly activated Akt) and activated $\beta$-catenin or PTEN mutants. These findings suggest that researchers should consider the possibility for synergistic effects that cannot be fully controlled for between INF stimulation and the gene of interest.

Self-renewal has been proposed to require the concurrence of three events: proliferation while preventing apoptosis and blocking differentiation (Zhang and Li 2005). By studying the combined effects of Pten and active $\beta$-catenin mutants using a more refined animal model, we found that expansion of phenotypic HSCs is cooperatively controlled by the PTEN/Akt and Wnt/ $\beta$-catenin pathways via a mechanism consistent with this tripartite view of self-renewal. While neither pathway alone is sufficient to promote self-renewal, in combination these pathways provide the necessary components of self-renewal. At the stem cell level, interaction between these two pathways is key, with each component making cooperative as well as unique contributions to HSC expansion, which is not evident in studying either single individually. Mechanistically, $\beta$-catenin activation results in reduced expression of multiple transcription factors critical to lineage differentiation and up-regulation of $I d 2$, which we showed to functionally impair myeloid differentiation. In double mutants, loss of Pten results in up-regulation of anti-apoptotic $\mathrm{Mcl}-\mathrm{L}_{\mathrm{L}}$, resulting in HSC self-renewal and expansion (Fig. 7E).

The long-term proliferation potential of HSCs must be maintained throughout an organism's life span-potential that is generally compromised by loss of quiescence (Fleming et al. 2008). Indeed, substantial proliferation normally leads to HSC exhaustion and loss of long-term functional capacity (North and Goessling 2010). Balancing substantial expansion with retention of long-term functional capacity remains a challenge for the ex vivo expansion of HSCs. Our double mutant mouse model uniquely expands the CD $34^{-}$fraction of LSK cells-a subpopulation enriched in quiescent HSCs that exclusively supports long-term hematopoiesis (Wilson et al. 2008). Similarly, our culture protocol derived from this double mutant expands functional LT-HSCs specifically when pharmacological activators of both pathways are used. GSK3 $\beta$ inhibitors or RNAi knockdown of GSK3 $\beta$ has been shown to enhance repopulation or moderately expand phenotypic HSCs in vivo (Trowbridge et al. 2006; Huang et al. 2009), and here we further this work by demonstrating the ex vivo expansion of functional LTHSCs using GSK3 $\beta$ inhibitors in addition to cooperative interaction of this pathway with the PI3K/Akt pathway.

During development or in response to acute stress, HSCs are capable of considerable expansion in vivo and are the most extensively studied stem cell system. Paradoxically, HSCs remain difficult to expand in culture, although progress has been achieved (Antonchuk et al. 2002; Reya et al. 2003; CC Zhang et al. 2006; Boitano et al. 2010; Butler et al. 2010; Delaney et al. 2010; Himburg et al. 2010). Pleiotrophin has been recently shown to expand human HSCs in vitro, in part by activating PI3K signaling (Himburg et al. 2010). Also, prostaglandin E2 (PGE2), which enhances HSC engraftment, has been shown to activate Wnt signaling (North et al. 2007; Goessling et al. 2009). Similarly, in vivo administration of GSK3 $\beta$ inhibitor or genetic knockdown of GSK3 $\beta$ in vivo has also been shown to expand HSCs (Trowbridge et al. 2006; Huang et al. 2009). However, only modest HSC expansion is consistently achieved, while more significant expansion is usually coupled with substantial differentiation. Generally, ex vivo expansion protocols fail to expand the most primitive HSCs with longterm potential. This is particularly the case for human HSPC expansion studies. Furthermore, ex vivo expansion protocols often use genetically modified cells or feeder layers, which may present difficulties in translating to a clinical setting (Butler et al. 2010). Inspired and informed by our genetic mutant system, we developed an ex vivo HSC expansion protocol. Using factors that regulate both the PI3K and $\beta$-catenin pathways, our ex vivo HSC expansion protocol partially mimics the genetic model; however, most importantly, this reversible approach allows for expansion of normal functional LTHSCs, the progeny of which can perform equivalently to a 100-fold greater dosage of uncultured cells, even in third-generation serial transplant recipients. Notably, the addition of GSK3 $\beta$ inhibitor to PI3K-stimulating medium using our protocol allows expansion without compromising long-term potential. Beyond this unprecedented level of functional LT-HSC expansion, there are numerous practical advantages with our culture system. Our protocol allows for the culture of unsorted, mixed populations of cells as the initial input population. As recently noted, preisolation of HSPCs may have several disadvantages, including substantial loss of the desired cells or functional capacity during the isolation procedure /Chou et al. 2010). Just as importantly, successful grafts also require less primitive progenitor cells to generate short-term rescue (Chou et al. 2010; Delaney et al. 2010), and our protocol also expands these radioprotective cells. By employing a serum-free medium with relatively low concentrations 
of only two cytokines, but without the need for feeder layers, genetically modified cells, fresh BM, or large cell doses for radioprotection, our culture system may have clinical value if developed for humans. We are currently pursuing this goal.

\section{Materials and methods}

\section{Animals}

All mice used in this study were housed in the animal facility at Stowers Institute for Medical Research (SIMR) and handled according to institute and NIH guidelines. All procedures were approved by the Institutional Animal Care and Use Committee of SIMR. Primary Scl-Cre mice were induced by intraperitoneal injection of tamoxifen every day for $5 \mathrm{~d}$, using $5 \mathrm{mg}$ on day 1 and $2 \mathrm{mg}$ on days $2-5$, each dissolved in $0.1 \mathrm{~mL}$ of corn oil. Transplantation experiments using the Scl-Cre model involved sorting LSK Flk2 ${ }^{-}$cells from Cre-negative (control), single mutants, and double mutants containing the $Z / E G$ reporter. One-thousand LSK Flk2 ${ }^{-}$cells along with $2 \times 10^{5}$ competitor/rescue whole BM cells were transplanted into each lethally irradiated (10 Gy) Ptprc (CD45.1) recipient. Mice transplanted with Scl-Cre LSK Flk2cells were induced by replacement of normal feed with feed containing $1 \mathrm{mg}$ of tamoxifen per gram of feed for $2 \mathrm{wk}$. $\beta$-Catenin loss-of-function studies (Fig. 4E) were performed by transplantation of $2 \times 10^{6}$ whole BM cells from Mx1-Cre-negative control and Mx1-Cre-positive single and double mutant donors into lethally irradiated Ptprc recipients, with induction at $3 \mathrm{wk}$ posttransplant using five doses of $250 \mu \mathrm{g}$ of polyI:C every other day. Scl-Cre, Pten, $\beta$-cat ${ }^{A c t}$, and $\beta$-cat ${ }^{-/-}$mice were obtained from Joachim Goethert (University of Duisburg, Essen, Germany), Hong Wu (University of California at Los Angeles, Los Angeles, CA), Makoto Taketo (Kyoto University, Japan), and the Jackson Laboratory, respectively.

\section{Ex vivo HSC expansion}

HSC expansion medium (ST + insulin medium) consists of StemSpan SFEM medium (Stem Cell Technologies) supplemented with $10 \mu \mathrm{g} / \mathrm{mL}$ heparin (Sigma), $0.5 \times$ penicillin/streptomycin (Sigma), $10 \mathrm{ng} / \mathrm{mL}$ recombinant mouse $(\mathrm{rm})$ SCF (Biovision, Inc.), and $20 \mathrm{ng} / \mathrm{mL}$ Tpo (Cell Sciences, Inc.). CHIR99021 (250 $\mathrm{nM})$ (Stemgent) was added where indicated. BM cells were harvested from $\mathrm{C} 57 \mathrm{Bl} / 6$ (CD45.2) mice and made into a singlecell suspension by gently drawing through a 22-gauge needle three to five times. Because red blood cell (RBC) lysis was determined to severely inhibit functional HSC expansion, cells were not exposed to any RBC lysis procedure. Instead, MNCs were isolated from mouse BM using Histopaque 1077 (Sigma) according to the manufacturer's instructions. Cells were washed and resuspended in HSC expansion medium. Total nucleated cell counts were obtained using a Quanta cell counter (BeckmanCoulter, Inc.) and a fraction of MNCs or whole BM cells were stained for FACS analysis. Frequency of LSK Flk ${ }^{-}$cells was determined by analyzing $>3 \times 10^{5}$ cells per sample independently in triplicate. MNCs were then plated at 50 LSK Flk2 ${ }^{-}$ cells along with $1.7 \times 10^{4}$ to $5.0 \times 10^{4} \mathrm{MNCs}$, depending on frequency of putative HSCs in the particular sample (ranging from $0.1 \%-0.3 \%$ ), in $200 \mu \mathrm{L}$ of HSC expansion medium per well in a 96-well U-bottom plate (Becton Dickinson and Company, catalog no. 353077). For sorted cultures, LSK Flk2- cells were sorted into 96-well U-bottom plates at 100 LSK Flk2 ${ }^{-}$cells per well. Cells were incubated at $37^{\circ} \mathrm{C}$ with $5 \% \mathrm{CO}_{2}$ and $5 \% \mathrm{O}_{2}$ (balance $\mathrm{N}_{2}$ ) for $14 \mathrm{~d}$. Cultures were checked daily, and cell pellets accumulating at the bottom of each U-shaped well that exceeded $2 \mathrm{~mm}$ in diameter were split by transferring one-half of the culture into a fresh well. It is critical for optimal HSC expansion that cell pellets are maintained at a density of 1-2 mm in size. One-half volume of medium was replaced every 2-3 d. After $14 \mathrm{~d}$ of culture, the total culture product was harvested, and cells were washed and resuspended in DMEM (Invitrogen, catalog no. 31053) in a volume corresponding to five original input LSK Flk2 $2^{-}$cells per $100 \mu \mathrm{L}$ for unsorted HSC cultures or 100 original input putative HSCs per $100 \mu \mathrm{L}$ for sorted HSC cultures. For competitive repopulation assays, $1 \times 10^{5} \mathrm{BM}$ cells congenic with the host $\left(\mathrm{CD} 45.1^{+}\right)$were included per mouse. One-hundred microliters of cultured cells or cells freshly isolated and quantified in the same manner were transplanted intravenously into lethally irradiated (10 Gy) Ptprc (CD45.1) recipient mice. Mice were placed on Baytril water 3 d prior to irradiation, which continued for 2 wk post-irradiation. Repopulation was measured every 4 wk post-transplant by collection of peripheral blood, RBC lysis, and staining of CD45.1 (recipient) versus CD45.2 (donor) engraftment. Multilineage reconstitution was determined by CD3, B220 (for T and B lymphoid, respectively), Gr1, and Mac-1 (for myeloid) gating on donor $\left(\mathrm{CD} 45.2^{+}\right)$cells. For $2^{\circ}$ and $3^{\circ}$ transplantation, the original, $1^{\circ}$, or $2^{\circ}$ transplant recipients were sacrificed, and BM was harvested from the femur, made into a single-cell suspension, and strained through a $70-\mu \mathrm{m}$ cell strainer. BM cells were counted and transplanted as above at a dosage of $1 \times 10^{6}$ per mouse.

\section{Flow cytometic analysis}

For phenotype analysis, hematopoietic cells were harvested from $\mathrm{BM}$ (femur and tibia), the spleen, peripheral blood, and the thymus. Red blood cells were lysed using a $0.16 \mathrm{M}$ ammonium chloride solution. For cell surface phenotyping, a lineage cocktail (Lin) was used, including CD3, CD4, CD8, Mac-1, Gr1, B220, IgM, and Ter119 (eBioscience). Monoclonal antibodies against Sca-1, Kit, Flk2, IL-7R $\alpha$, CD34, CD16/32 (Fc $\gamma$ RII/III), CD44, CD25, CD45.1, and CD45.2 were also used where indicated. Cell sorting and analysis were performed using a MoFlo (Dako) and/or CyAn ADP (Dako). Data analysis was performed using FlowJo software.

\section{Single-cell HSC genotyping}

LSK CD34- cells were sorted into 96-well plates (one cell per well) containing $50 \mu \mathrm{L}$ of MethoCult complete medium (M3434; Stem Cell Technologies) and incubated $\left(37^{\circ} \mathrm{C}, 5 \% \mathrm{CO}_{2}\right)$ for $12-14$ d. DNA was purified from single colonies using QIAamp DNA Blood kit (Qiagen).

\section{Apoptosis analysis}

Apoptosis and cell death were measured by AnnexinV and Sytox Green staining according to the manufacturer's instructions (Vybrant Apoptosis kit \#9, Invitrogen).

\section{Microarray}

RNA was isolated from LSK Flk2 $2^{-}$cells sorted from MNCs cultured for $12 \mathrm{~d}$ in ST medium and then induced with OHT $48 \mathrm{~h}$ prior to sorting. MouseGenome430_2 arrays were scanned with a GeneChip Scanner 3000 7G using GeneChip Fluidics Station 450 and GeneChip operating software (GCOS 1.4).

\section{$q R T-P C R$}

MNCs were cultured in ST + insulin medium for $12 \mathrm{~d}$ prior to addition of OHT $(1 \mu \mathrm{M})$ and cultured for an additional $48 \mathrm{~h}$. LSK 
Flk2 $2^{-}$cells were sorted to $>90 \%$ purity. TaqMan gene expression assays (Applied Biosystems) were performed on triplicate samples using a 7900HT fast real-time PCR system (Applied Biosystems).

\section{Telomerase assay}

Telomerase activity was quantified using the TRAPeze XL telomerase detection kit (Millipore) according to the manufacturer's protocol.

\section{Lentiviral transduction}

Mice were treated with $150 \mu \mathrm{g} / \mathrm{g} 5$-FU to enrich for HSPCs and to induce cell cycling. Four days later, BM was cultured overnight in ST medium and transduced by Magnetofection using ViroMag $\mathrm{R} / \mathrm{L}$ particles according to the manufacturer's protocol $/ \mathrm{OZ}$ Biosciences).

\section{CFU analysis}

CFU assays were performed using MethoCult complete medium (M3434; Stem Cell Technologies) according to the manufacturer's protocol. CFUs were scored after $12 \mathrm{~d}$ of incubation.

\section{Immunostaining}

Cells were sorted onto lysine-coated slides, fixed with methanol, and stained for Mcl-1 $\mathrm{L}_{\mathrm{L}}$ (K-20; sc-958, Santa Cruz Biotechnology) using 1:200 dilution, pAkt Ser 473 (736E11, Cell Signaling) using 1:50 dilution, or anti- $\beta$-galactosidase (100-4136, Rockland, Inc.) using 1:100 dilution.

\section{Statistical analyses}

Data were expressed as mean \pm SD. Pairwise comparisons were performed using Student's $t$-test.

\section{Acknowledgments}

We thank Ariel Paulson, Chris Seidel, and Hua Li for assistance with microarray analysis. We also thank Joachim Goethert (University of Duisburg-Essen, Germany) and Telethon Institute for Child Health Research for providing HSC-SCL-Cre-ER ${ }^{T}$ mice; Hong Wu (University of California at Los Angeles, Los Angeles, CA) for providing Pten conditional mutant mice; Makoto Taketo (Kyoto University, Japan) for providing the conditional $\beta$-cat ${ }^{A c t}$ mutants; Karen Tannen for proofreading and editing; Mark Hembree, Teri Johnson, Heather Marshall, Kim Westpfahl, Erin Redenbaugh, and Deborah Dukes for technical support; and members of the Li laboratory for scientific discussion. This work was funded by the Stowers Institute for Medical Research. J.M.P is a Fellow of the Leukemia and Lymphoma Society. R.S. is a PhD student registered with the Open University.

\section{References}

Akashi K, Traver D, Miyamoto T, Weissman IL. 2000. A clonogenic common myeloid progenitor that gives rise to all myeloid lineages. Nature 404: 193-197.

Akashi K, He X, Chen J, Iwasaki H, Niu C, Steenhard B, Zhang J, Haug J, Li L. 2003. Transcriptional accessibility for genes of multiple tissues and hematopoietic lineages is hierarchically controlled during early hematopoiesis. Blood 101: 383-389.

Antonchuk J, Sauvageau G, Humphries RK. 2002. HOXB4induced expansion of adult hematopoietic stem cells ex vivo. Cell 109: 39-45.
Baba Y, Garrett KP, Kincade PW. 2005. Constitutively active $\beta$-catenin confers multilineage differentiation potential on lymphoid and myeloid progenitors. Immunity 23: 599-609.

Blanpain C, Fuchs E. 2009. Epidermal homeostasis: a balancing act of stem cells in the skin. Natl Rev 10: 207-217.

Boitano AE, Wang J, Romeo R, Bouchez LC, Parker AE, Sutton SE, Walker JR, Flaveny CA, Perdew GH, Denison MS, et al. 2010. Aryl hydrocarbon receptor antagonists promote the expansion of human hematopoietic stem cells. Science 329: 1347-1348.

Borowitz MJ, Guenther KL, Shults KE, Stelzer GT. 1993. Immunophenotyping of acute leukemia by flow cytometric analysis. Am J Clin Pathol 100: 534-540.

Butler JM, Nolan DJ, Vertes EL, Varnum-Finney B, Kobayashi H, Hooper AT, Seandel M, Shido K, White IA, Kobayashi M, et al. 2010. Endothelial cells are essential for the self-renewal and repopulation of Notch-dependent hematopoietic stem cells. Cell Stem Cell 6: 251-264.

Chou S, Chu P, Hwang W, Lodish H. 2010. Expansion of human cord blood hematopoietic stem cells for transplantation. Cell Stem Cell 7: 427-428.

Christensen JL, Weissman IL. 2001. Flk-2 is a marker in hematopoietic stem cell differentiation: a simple method to isolate long-term stem cells. Proc Natl Acad Sci 98: 1454114546.

Cobas M, Wilson A, Ernst B, Mancini SJ, MacDonald HR, Kemler R, Radtke F. 2004. $\beta$-Catenin is dispensable for hematopoiesis and lymphopoiesis. J Exp Med 199: 221-229.

Datta SR, Dudek H, Tao X, Masters S, Fu H, Gotoh Y, Greenberg ME. 1997. Akt phosphorylation of BAD couples survival signals to the cell-intrinsic death machinery. Cell 91: 231-241.

Delaney C, Heimfeld S, Brashem-Stein C, Voorhies H, Manger RL, Bernstein ID. 2010. Notch-mediated expansion of human cord blood progenitor cells capable of rapid myeloid reconstitution. Nat Med 16: 232-236.

Doulatov S, Notta F, Rice KL, Howell L, Zelent A, Licht JD, Dick JE. 2009. PLZF is a regulator of homeostatic and cytokine-induced myeloid development. Genes Dev 23: 2076-2087.

Enver T, Greaves M. 1998. Loops, lineage, and leukemia. Cell 94: 9-12.

Essers MA, Offner S, Blanco-Bose WE, Waibler Z, Kalinke U, Duchosal MA, Trumpp A. 2009. IFN $\alpha$ activates dormant haematopoietic stem cells in vivo. Nature 458: 904-908.

Fleming HE, Janzen V, Lo Celso C, Guo J, Leahy KM, Kronenberg HM, Scadden DT. 2008. Wnt signaling in the niche enforces hematopoietic stem cell quiescence and is necessary to preserve self-renewal in vivo. Cell Stem Cell 2: 274-283.

Goessling W, North TE, Loewer S, Lord AM, Lee S, StoickCooper CL, Weidinger G, Puder M, Daley GQ, Moon RT, et al. 2009. Genetic interaction of PGE2 and Wnt signaling regulates developmental specification of stem cells and regeneration. Cell 136: 1136-1147.

Gothert JR, Gustin SE, Hall MA, Green AR, Gottgens B, Izon DJ, Begley CG. 2005. In vivo fate-tracing studies using the Scl stem cell enhancer: embryonic hematopoietic stem cells significantly contribute to adult hematopoiesis. Blood 105: 2724-2732.

Guo W, Lasky JL, Chang CJ, Mosessian S, Lewis X, Xiao Y, Yeh JE, Chen JY, Iruela-Arispe ML, Varella-Garcia M, et al. 2008. Multi-genetic events collaboratively contribute to Pten-null leukaemia stem-cell formation. Nature 453: 529-533.

Harada N, Tamai Y, Ishikawa T, Sauer B, Takaku K, Oshima M, Taketo MM. 1999. Intestinal polyposis in mice with a dominant stable mutation of the $\beta$-catenin gene. EMBO $J$ 18: 5931-5942. 
He XC, Yin T, Grindley JC, Tian Q, Sato T, Tao WA, Dirisina R, Porter-Westpfahl KS, Hembree M, Johnson T, et al. 2007. PTEN-deficient intestinal stem cells initiate intestinal polyposis. Nat Genet 39: 189-198.

Himburg HA, Muramoto GG, Daher P, Meadows SK, Russell JL, Doan P, Chi J-T, Salter AB, Lento WE, Reya T, et al. 2010. Pleiotrophin regulates the expansion and regeneration of hematopoietic stem cells. Nat Med 16: 475-482.

Hu M, Krause D, Greaves M, Sharkis S, Dexter M, Heyworth C, Enver T. 1997. Multilineage gene expression precedes commitment in the hemopoietic system. Genes Dev 11: 774-785.

Huang J, Zhang Y, Bersenev A, O'Brien WT, Tong W, Emerson SG, Klein PS. 2009. Pivotal role for glycogen synthase kinase3 in hematopoietic stem cell homeostasis in mice. I Clin Invest 119: 3519-3529.

Jeannet G, Scheller M, Scarpellino L, Duboux S, Gardiol N, Back J, Kuttler F, Malanchi I, Birchmeier W, Leutz A, et al. 2008. Long-term, multilineage hematopoiesis occurs in the combined absence of $\beta$-catenin and $\gamma$-catenin. Blood 111: 142149.

Ji M, Li H, Suh HC, Klarmann KD, Yokota Y, Keller JR. 2008. Id2 intrinsically regulates lymphoid and erythroid development via interaction with different target proteins. Blood 112: 1068-1077.

Kirstetter P, Anderson K, Porse BT, Jacobsen SE, Nerlov C. 2006. Activation of the canonical Wnt pathway leads to loss of hematopoietic stem cell repopulation and multilineage differentiation block. Nat Immunol 7: 1048-1056.

Koch U, Wilson A, Cobas M, Kemler R, Macdonald HR, Radtke F. 2008. Simultaneous loss of $\beta$ - and $\gamma$-catenin does not perturb hematopoiesis or lymphopoiesis. Blood 111: 160-164.

Kondo M, Weissman IL, Akashi K. 1997. Identification of clonogenic common lymphoid progenitors in mouse bone marrow. Cell 91: 661-672.

Lesche R, Groszer M, Gao J, Wang Y, Messing A, Sun H, Liu X, $\mathrm{Wu} \mathrm{H}$. 2002. Cre/loxP-mediated inactivation of the murine Pten tumor suppressor gene. Genesis 32: 148-149.

Li J, Sarosi I, Cattley RC, Pretorius J, Asuncion F, Grisanti M, Morony S, Adamu S, Geng Z, Qiu W, et al. 2006. Dkk1mediated inhibition of Wnt signaling in bone results in osteopenia. Bone 39: 754-766.

Li H, Ji M, Klarmann KD, Keller JR. 2010. Repression of Id2 expression by Gfi-1 is required for B-cell and myeloid development. Blood 116: 1060-1069.

Maira SM, Stauffer F, Brueggen J, Furet P, Schnell C, Fritsch C, Brachmann S, Chene P, De Pover A, Schoemaker K, et al. 2008. Identification and characterization of NVP-BEZ235, a new orally available dual phosphatidylinositol 3-kinase/ mammalian target of rapamycin inhibitor with potent in vivo antitumor activity. Mol Cancer Ther 7: 1851-1863.

Malhotra S, Kincade PW. 2009. Wnt-related molecules and signaling pathway equilibrium in hematopoiesis. Cell Stem Cell 4: 27-36.

Miller CL, Eaves CJ. 1997. Expansion in vitro of adult murine hematopoietic stem cells with transplantable lympho-myeloid reconstituting ability. Proc Natl Acad Sci 94: 1364813653.

Miyamoto T, Iwasaki H, Reizis B, Ye M, Graf T, Weissman IL, Akashi K. 2002. Myeloid or lymphoid promiscuity as a critical step for hematopoietic lineage commitment. Dev Cell 3: 137-147.

Morrison SJ, Kimble J. 2006. Asymmetric and symmetric stemcell divisions in development and cancer. Nature 441: 1068 1074.

Murdoch B, Chadwick K, Martin M, Shojaei F, Shah KV, Gallacher L, Moon RT, Bhatia M. 2003. Wnt-5A augments repopulating capacity and primitive hematopoietic development of human blood stem cells in vivo. Proc Natl Acad Sci 100: $3422-3427$.

Na Nakorn T, Traver D, Weissman IL, Akashi K. 2002. Myeloerythroid-restricted progenitors are sufficient to confer radioprotection and provide the majority of day 8 CFU-S. J Clin Invest 109: 1579-1585.

Nemeth MJ, Topol L, Anderson SM, Yang Y, Bodine DM. 2007. Wnt5a inhibits canonical Wnt signaling in hematopoietic stem cells and enhances repopulation. Proc Natl Acad Sci 104: $15436-15441$.

North TE, Goessling W. 2010. Previews. NOTCHing an arrow at cord blood: translating stem cell knowledge into clinical practice. Cell Stem Cell 6: 186-187.

North TE, Goessling W, Walkley CR, Lengerke C, Kopani KR, Lord AM, Weber GJ, Bowman TV, Jang IH, Grosser T, et al. 2007. Prostaglandin E2 regulates vertebrate haematopoietic stem cell homeostasis. Nature 447: 1007-1011.

Novak A, Guo C, Yang W, Nagy A, Lobe CG. 2000. Z/EG, a double reporter mouse line that expresses enhanced green fluorescent protein upon Cre-mediated excision. Genesis 28: 147-155.

Opferman JT, Iwasaki H, Ong CC, Suh H, Mizuno S, Akashi K, Korsmeyer SJ. 2005. Obligate role of anti-apoptotic MCL-1 in the survival of hematopoietic stem cells. Science 307: 11011104.

Orkin SH. 2000. Diversification of haematopoietic stem cells to specific lineages. Nat Rev Genet 1: 57-64.

Orkin SH, Zon LI. 2008. Hematopoiesis: an evolving paradigm for stem cell biology. Cell 132: 631-644.

Osawa M, Hanada K, Hamada H, Nakauchi H. 1996. Long-term lymphohematopoietic reconstitution by a single CD34-low/ negative hematopoietic stem cell. Science 273: 242-245.

Purton LE, Scadden DT. 2007. Limiting factors in murine hematopoietic stem cell assays. Cell Stem Cell 1: 263-270.

Reya T, Morrison SJ, Clarke MF, Weissman IL. 2001. Stem cells, cancer, and cancer stem cells. Nature 414: 105-111.

Reya T, Duncan AW, Ailles L, Domen J, Scherer DC, Willert K, Hintz L, Nusse R, Weissman IL. 2003. A role for Wnt signalling in self-renewal of haematopoietic stem cells. Nature 423: 409-414.

Rossi DJ, Weissman IL. 2006. Pten, tumorigenesis, and stem cell self-renewal. Cell 125: 229-231.

Salmena L, Carracedo A, Pandolfi PP. 2008. Tenets of PTEN tumor suppression. Cell 133: 403-414.

Sato N, Meijer L, Skaltsounis L, Greengard P, Brivanlou AH. 2004. Maintenance of pluripotency in human and mouse embryonic stem cells through activation of Wnt signaling by a pharmacological GSK-3-specific inhibitor. Nat Med 10: 5563.

Sauvageau G, Thorsteinsdottir U, Eaves CJ, Lawrence HI, Largman C, Lansdorp PM, Humphries RK. 1995. Overexpression of HOXB4 in hematopoietic cells causes the selective expansion of more primitive populations in vitro and in vivo. Genes Dev 9: 1753-1765.

Scadden DT. 2006. The stem-cell niche as an entity of action. Nature 441: 1075-1079.

Scheller M, Huelsken J, Rosenbauer F, Taketo MM, Birchmeier W, Tenen DG, Leutz A. 2006. Hematopoietic stem cell and multilineage defects generated by constitutive $\beta$-catenin activation. Nat Immunol 7: 1037-1047.

Trowbridge JJ, Xenocostas A, Moon RT, Bhatia M. 2006. Glycogen synthase kinase-3 is an in vivo regulator of hematopoietic stem cell repopulation. Nat Med 12: 89-98.

van de Wetering M, Sancho E, Verweij C, de Lau W, Oving I, Hurlstone A, van der Horn K, Batlle E, Coudreuse D, 


\section{Perry et al.}

Haramis AP, et al. 2002. The $\beta$-catenin/TCF-4 complex imposes a crypt progenitor phenotype on colorectal cancer cells. Cell 111: 241-250.

Willert K, Brown JD, Danenberg E, Duncan AW, Weissman IL, Reya T, Yates JR 3rd, Nusse R. 2003. Wnt proteins are lipidmodified and can act as stem cell growth factors. Nature 423: 448-452.

Wilson A, Laurenti E, Oser G, van der Wath RC, Blanco-Bose W, Jaworski M, Offner S, Dunant CF, Eshkind L, Bockamp E, et al. 2008. Hematopoietic stem cells reversibly switch from dormancy to self-renewal during homeostasis and repair. Cell 135: 1118-1129.

Xie Y, Yin T, Wiegraebe W, He XC, Miller D, Stark D, Perko K, Alexander R, Schwartz J, Grindley JC, et al. 2009. Detection of functional haematopoietic stem cell niche using real-time imaging. Nature 457: 97-101.

Yilmaz OH, Valdez R, Theisen BK, Guo W, Ferguson DO, Wu H, Morrison SJ. 2006. Pten dependence distinguishes haematopoietic stem cells from leukaemia-initiating cells. Nature 441: 475-482.

Ying Q-L, Wray J, Nichols J, Batlle-Morera L, Doble B, Woodgett I, Cohen P, Smith A. 2008. The ground state of embryonic stem cell self-renewal. Nature 453: 519-523.

Zhang J, Li L. 2005. BMP signaling and stem cell regulation. Dev Biol 284: 1-11.

Zhang CC, Lodish HF. 2005. Murine hematopoietic stem cells change their surface phenotype during ex vivo expansion. Blood 105: 4314-4320.

Zhang CC, Kaba M, Ge G, Xie K, Tong W, Hug C, Lodish HF. 2006. Angiopoietin-like proteins stimulate ex vivo expansion of hematopoietic stem cells. Nat Med 12: 240-245.

Zhang J, Grindley JC, Yin T, Jayasinghe S, He XC, Ross JT, Haug JS, Rupp D, Porter-Westpfahl KS, Wiedemann LM, et al. 2006. PTEN maintains haematopoietic stem cells and acts in lineage choice and leukaemia prevention. Nature 441: 518522.

Zhao C, Blum J, Chen A, Kwon HY, Jung SH, Cook JM, Lagoo A, Reya T. 2007. Loss of $\beta$-catenin impairs the renewal of normal and CML stem cells in vivo. Cancer Cell 12: 528541. 


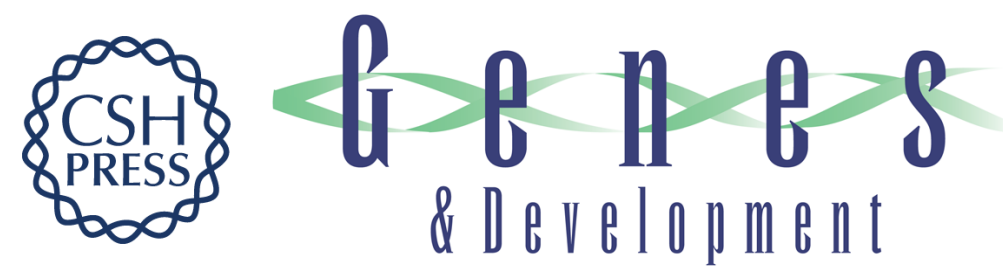

\section{Cooperation between both Wnt/ $\beta$-catenin and PTEN/PI3K/Akt signaling promotes primitive hematopoietic stem cell self-renewal and expansion}

John M. Perry, Xi C. He, Ryohichi Sugimura, et al.

Genes Dev. 2011, 25: originally published online September 2, 2011

Access the most recent version at doi:10.1101/gad.17421911

Supplemental Material

References

License

Email Alerting

Service
http://genesdev.cshlp.org/content/suppl/2011/09/01/gad.17421911.DC1

This article cites 69 articles, 19 of which can be accessed free at: http://genesdev.cshlp.org/content/25/18/1928.full.html\#ref-list-1

Receive free email alerts when new articles cite this article - sign up in the box at the top right corner of the article or click here.

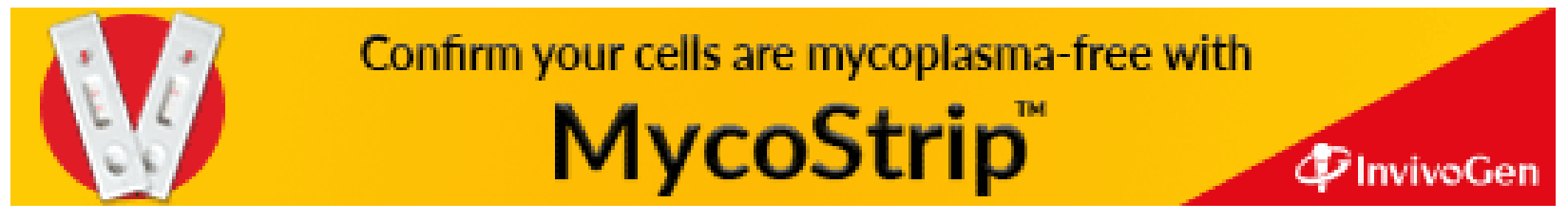

